\title{
Analogs of LDL Receptor Ligand Motifs in Dengue Envelope and Capsid Proteins as Potential Codes for Cell Entry
}

\author{
Juan Guevara Jr., Jaime Romo Jr., Troy McWhorter, and Natalia Valentinova Guevara \\ Biophysics Research Laboratory, Department of Physics and Astronomy, University of Texas at Brownsville, \\ One West University Boulevard, Brownsville, TX 78520, USA
}

Correspondence should be addressed to Natalia Valentinova Guevara; natalia.guevara@utb.edu

Received 9 December 2014; Revised 17 March 2015; Accepted 17 March 2015

Academic Editor: Tatiana Betakova

Copyright (C) 2015 Juan Guevara Jr. et al. This is an open access article distributed under the Creative Commons Attribution License, which permits unrestricted use, distribution, and reproduction in any medium, provided the original work is properly cited.

It is established that cell entry of low density lipoprotein particles (LLPs) containing Apo B100 and Apo E is mediated by receptors and GAGs. Receptor ligand motifs, XBBBXXBX, XBBXBX, and $\Psi \mathbf{B} \Psi \mathrm{XB}$, and mono- and bipartite NLS sequences are abundant in Apo E and Apo B100 as well as in envelope and capsid proteins of dengue viruses 1-4 (DENV1-4). Synthetic, fluorescence-labeled peptides of sequences in DENV2 envelope protein, and DENV3 capsid that include these motifs were used to conduct a qualitative assessment of cell binding and entry capacity using HeLa cells. DENV2 envelope peptide, Dsp2EP, ${ }^{0564}$ Gly-Gly ${ }^{0595}$, was shown to bind and remain at the cell surface. In contrast, DENV3 capsid protein peptide, Dsp3CP, ${ }^{0002} \mathrm{Asn}-\mathrm{Gln}{ }^{0028}$, readily enters HeLa cells and accumulates at discrete loci in the nucleus. FITC-labeled dengue synthetic peptides colocalize with low density lipoproteinCM-DiI and Apo E-CM-DiI to a degree suggesting that dengue viruses may utilize cell entry pathways used by LLPs.

\section{Introduction}

The Flaviviridae viruses and low density lipoparticles (LLPs), low density lipoproteins (LDL), intermediate density lipoproteins (IDL) and very low density lipoproteins (VLDL), are unrelated biological entities. Nevertheless, there are many striking similarities between viral particles and LLPs that have been largely overlooked. Flaviviruses and LLPs are similar in a general sense as both include lipids and proteins arranged in roughly spherical structures. Flaviviruses are approximately $500 \AA$ in diameter [1] while LLPs range in size from 250 to $600 \AA[2,3]$. Intriguing, proteins of Flaviviridae and LLP have similar capacities to enclose, protect, transport, and deliver nucleic acids to cytoplasm and/or cell nucleus $[4,5]$. Lipids in both are essential for conformational integrity and functionality of the proteins.

The Flaviviridae family includes three genera of positive, single-strand RNA viruses, Flavivirus, Hepacivirus, and Pestivirus [6]. These arthropod-vectored human pathogenic viruses are emerging threats to first world nations [7]. Flaviviruses are characterized by an outer "envelope" that protects and delivers the encapsulated genome. The outer envelope is comprised of a bilayer lipid membrane, derived from the host cell endoplasmic reticulum [8], and two glycoproteins, $\mathrm{M}$ and envelope glycoprotein $\mathrm{E}$ [9]. In dengue viruses 1-4 (DENV1-4), the outer envelope contains 90 dimers of glycoprotein $\mathrm{E}$ each associated with a protein $\mathrm{M}$ [1]. Many viruses, including the Flaviviridae, use receptormediated pathways for cell entry [9]. Clathrin-mediated endocytosis of dengue has been suggested [10-13]. Domain III of the DENV envelope protein is thought to be essential for cell entry; however, specific receptor ligand motifs in dengue structural proteins have not been identified [6-14].

LLPs are characterized by a single molecule of apolipoprotein B100 (Apo B100), multiple copies of apolipoprotein E (Apo E), and other apolipoproteins such as apo C-I, C-II, C-III, A-I, A-II, A-IV, and M $[15,16]$. LLPs include mainly phospholipids, cholesterol, cholesterol esters, and triglycerides [17, 18], arranged in pseudomicelles with a monolayer of phospholipid on the surface and a hydrophobic core. Endocytosis, which involves cell surface receptors and clathrin-coated endosomes, was elucidated for LDL and other LLPs first by Goldstein and Brown [19]. Apo $\mathrm{B} 100$ and Apo E contain motifs that bind LDL B/E receptors and other proteins of the LDL receptor-related superfamily

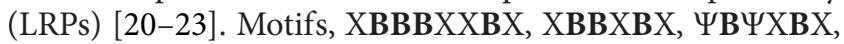


and XXВXXВXXXВB (Types I, II, III, and IV, resp.), where $\mathbf{B}$ can be Arginine or Lysine, $\Psi$ is a nonpolar amino acid, and $\mathrm{X}$ is any amino acid, are multifunctional motifs that impart the capacity to bind nucleic acids and other proteins, that is, receptors [21, 22, 24]. These motifs give LLPs a high affinity for GAGs, such as heparin and heparan sulfate. Binding of heparan sulfate proteoglycans (HSPG) may involve both GAG moieties and ligand-binding modules of the HSPG core protein [25].

In a previous report [5], we described structural similarities between Apo E and dengue capsid protein, PDB: 1LPE and $1 \mathrm{R} 6 \mathrm{R}$, respectively. Although their primary structures are not significantly similar, their secondary and tertiary structures are alike, that is, helix-loop-helix; and it has been confirmed experimentally that both proteins possess nucleic acid-binding and nuclear transit capacity $[26,27]$. The Apo E receptor ligand motifs and receptor binding domain are well established [28]; however, the exact cell entry "codes" have yet to be elucidated in Flavivirus envelope and capsid proteins.

Our present studies are based on the hypothesis that proteins of the LDL receptor gene family ubiquitously expressed in human and mosquito may be used by DENV for cell entry. Our goals were to identify potential receptor ligand motifs in dengue envelope and capsid proteins by sequence comparison to the motifs in Apo B100 and Apo E; use fluorescence-labeled synthetic peptides to assess cell binding/entry capacity of the viral proteins; and assess effects of LDL and Apo E on binding and uptake of viral peptides using live HeLa cells in culture. Our findings may have implications for intervention strategies in viral infections in general.

\section{Methods}

DENV polyprotein sequences used in this study were obtained from NIH NCBI PUBMED Protein and Structure databases.

2.1. Chemicals. Phosphate-buffered saline (PBS) and cell culture media were from Media Tech, Inc., Herndon, VA. Penicillin G-Sodium, streptomycin sulfate, Fetal Bovine Serum, Trypsin, Corning Costar 6- and 12-well culture plates, and 8-well Lab-Tek Chamber glass slides with cover were from Thermo Fisher Scientific, Inc. Mevastatin was from SigmaAldrich, Inc. Trypan Blue (modified) $0.4 \%$ solution in PBS was from MP Biomedicals, LLC, Solon, $\mathrm{OH}$.

2.2. Fluorescence-Labeled Peptides. Fluorescence-labeled synthetic peptides (Tables 1-3), of $95 \%$ or greater purity by HPLC analysis, were from NEO Group, Inc. Cambridge, MA. Peptides were received in lyophilized form in sealed $1 \mathrm{~mL}$ vials and solubilized in PBS- $10 \mathrm{mM} \mathrm{MgCl}_{2}$ to yield $1 \mathrm{mg} / \mathrm{mL}$.

2.3. Protein Labeling. Purified human Apo E (>95\%) was from Athens Research \& Technology, Athens GA. LDL was isolated as described previously [5] from pooled normal human plasma from Innovative Research, Inc., Movi, MI. For covalent labeling of the protein, $250 \mu \mathrm{L}$ of ethanol was added to the vial containing $50 \mu \mathrm{g}$ CM-DiI (7000), a thiol-reactive fluorescence compound from Invitrogen, Inc., to make a stock solution. Next, $1 \mu \mathrm{L}$ of CM-DiI stock solution was added to $150 \mu \mathrm{g}$ of Apo E in $500 \mu \mathrm{L}$ or to $1 \mathrm{mg}$ of purified LDL in $1 \mathrm{~mL}$ of PBS-5 mM MgCl 2 . These reaction mixtures were allowed to stand for 30 minutes at ambient temperature then dialyzed in 1 liter $\mathrm{PBS}-\mathrm{MgCl}_{2}$ with three changes overnight.

2.4. Cells. HeLa cells (human cervix epithelial adenocarcinoma cell line, CCL-2) were from American Type Culture Collection (ATCC). Typically, cells were stored in liquid Nitrogen until needed and then seeded and propagated according to ATCC protocols in DMEM supplemented with 10\% FBS, 100 units Penicillin G-Sodium, and 100 units/mL streptomycin sulfate (DMEM-P/S-FBS) at $37^{\circ} \mathrm{C}$ in an atmosphere of $5 \% \mathrm{CO}_{2}$ in a humidified incubator. Cells at $70 \%$ confluence were incubated overnight in DMEM-P/S$3 \%$ FBS medium containing $40 \mu \mathrm{M}$ mevastatin, after which medium was replaced with $1 \mathrm{~mL}$ PBS. Labeled peptides (alone or with a potential competitor for receptor binding, Apo E, Apo E-derived peptide, or LDL) were added to each well then incubated under same conditions as above. Timecourse and peptide concentration studies were conducted using FITC-labeled peptides to determine minimal concentration required to detect fluorescence signal, incubation period required for binding and/or uptake, and potential cytotoxicity. For Dsp2EP-FITC, $0.5-45 \mu \mathrm{g} / \mathrm{mL}$ of peptide $(0.2-10.6 \mu \mathrm{M})$ was used, and the cells were observed for 5$120 \mathrm{~min}$. Assays for Dsp3CP-FITC binding to HeLa cells were conducted using increasing concentrations of the peptide: $6.75 \mu \mathrm{M}, 13.5 \mu \mathrm{M}, 20.25 \mu \mathrm{M}, 27 \mu \mathrm{M}, 33.75 \mu \mathrm{M}, 40.5 \mu \mathrm{M}$, and $47.25 \mu \mathrm{M}$. Cells were monitored at 15-minute intervals for 60 minutes and experiment was terminated at 90-minute time point.

To reduce background fluorescence the assay mixture was removed and live cells were rinsed thrice with PBS. In quenching experiments cells were incubated at ambient temperature for 10 minutes using PBS with $0.2 \%$ Trypan Blue. Live cells were then rinsed with PBS sufficiently to visualize cells to obtain bright-light images as described below.

2.5. Dual Label Experiments. In these experiments, Dsp2EPFITC was used in combination with either Apo E-CM-DiI or LDL-CM-DiI. Cells in 8-chamber slides were preconditioned as routine and rinsed with PBS- $5 \mathrm{mM} \mathrm{MgCl}_{2}$, incubated for 15 minutes at ambient temperature in $100 \mu \mathrm{L}$ PBS- $\mathrm{MgCl}_{2}$ containing $5 \mu \mathrm{g}$ Dsp2EP-FITC mixed with $1.5 \mu \mathrm{g}$ Apo E-CMDiI or $5.0 \mu \mathrm{g}$ LDL-CM-DiI. Binding assay mix was removed and cells rinsed in PBS prior to microscopy analysis in $200 \mu \mathrm{L}$ PBS- $\mathrm{MgCl}_{2}$. Images of live cells were obtained as before using green and red filters. Overlay images of Dsp2EP-FITC (green fluorescence image) and Apo E-CM-DiI or LDL-CM-DiI (red fluorescence image) were created using Adobe Photoshop CS 4 as described below. Representative regions showing signals green, red, and yellow were enlarged and subjected to digital analysis using Image J. Color was split into channels red, blue, and green, and raw integrated densities for each color were rendered in $3 \mathrm{D}$. 
TABLE 1: LDL receptor ligand and NLS motifs in Apo E sequence.

\begin{tabular}{|c|c|c|c|c|}
\hline Type I & Type II & Type III & Mono NLS & Bipartite NLS \\
\hline ХВВBХХХВХ & XBBXBK & 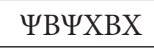 & XBBBX & BBXXXXXXXXXXBXBXB \\
\hline LRKRLLRD & LRKLLRK & $\begin{array}{l}\text { LKAYKS } \\
\text { ARLSKE }\end{array}$ & $\begin{array}{l}\text { RKLRKR } \\
\text { ERLRAR } \\
\text { SRTRDR }\end{array}$ & $\begin{array}{l}\text { RVRLASHLRKLRKRLLR } \\
\text { RLRARMEEMGSRTRDR }\end{array}$ \\
\hline E131 peptide & \multicolumn{4}{|c|}{${ }^{0131}$ EELRVRLASHLRKLRKRLLRDADDLQKRLAVYQAGAREGAERG ${ }^{0173}$-K-FITC } \\
\hline Apo E-2 peptide & \multicolumn{4}{|c|}{ NH2-STEELRVRLASHLRKLRKRLLRDADDLQKRLAVYTQHG-OH } \\
\hline
\end{tabular}

TABLE 2: Receptor ligand and NLS motifs in the dengue virus envelope proteins.

\begin{tabular}{|c|c|c|c|}
\hline Envelope proteins & $\Psi \mathbf{B} \Psi \mathrm{XB}$ & Mono & Bipartite \\
\hline \multicolumn{4}{|c|}{ Potential receptor ligand and nuclear localization signal motifs } \\
\hline DENV2 & $\begin{array}{c}\text { LRMDK } \\
\text { FKIVK }\end{array}$ & $\begin{array}{l}\text { LKCRLRM } \\
\text { MRGAKRM }\end{array}$ & KKGSSIGQMFETTMRGAKR \\
\hline Dsp2EP & \multicolumn{3}{|c|}{${ }^{0564}$ KCRLRMDKLQLKGMSYSMCTGKFKIVKEIAET-K-FITC } \\
\hline Dsp2EP (B) & \multicolumn{3}{|c|}{${ }^{0558}$ GHLKCRLDMDDLQLKGMSYSMCTGKFKIVKEIAETQHG-K-FITC } \\
\hline \multicolumn{4}{|c|}{${ }^{0558}$ GHLKCRLRMDKLQLKGMSYSMCTGKFDIVDEIAETQHG-K-FITC } \\
\hline \multicolumn{4}{|c|}{ Receptor ligand motifs in Dsp2EP, Apo E and Apo B100 } \\
\hline DENV2EP & ${ }^{0563} \mathrm{LK}$ & G-MSYSMCT & IAET $^{0595}$ \\
\hline Apo E & ${ }^{0067} \mathrm{TM}$ & EQLTPVAEETI & $\mathrm{QAA}^{0100}$ \\
\hline Apo B100 & ${ }^{3176} \mathrm{FDI}$ & DFVTKSYNE & KAEK $^{3209}$ \\
\hline Apo B100 & ${ }^{3181} \mathrm{EKI}$ & SYNETKIKFD & $\mathrm{HDEL}^{3214}$ \\
\hline Apo B100 & ${ }^{2604} \mathrm{NF}$ & $\operatorname{STP}\left(\mathrm{X}_{18}\right) \mathrm{EMK}$ & $\mathrm{M}^{2651}$ \\
\hline
\end{tabular}

In similar experiments, $50 \mu \mathrm{g}$ Dsp3CP-FITC was combined with $75 \mu \mathrm{g}$ Apo E-CM-DiI in $300 \mu \mathrm{L}$ PBS- $\mathrm{MgCl}_{2}$. Increasing volumes, $8,16,24,32$, and $40 \mu \mathrm{L}$, of this mixture were added to cells preconditioned as above in an 8-chamber slide in PBS- $\mathrm{MgCl}_{2}$ in $200 \mu \mathrm{L}$ assay. These were then incubated at $37^{\circ} \mathrm{C}$ for 15 and 90 minutes.

2.6. Fluorescence Microscopy. All images were obtained using live cells in $\mathrm{PBS}-\mathrm{MgCl}_{2}$ in culture trays or 8-well slides. Microscopy was performed using a Zeiss Axiovert 25 equipped with Zeiss objectives and FITC/GFP (Zeiss HQ470/40x and HQ525/50m) and red (Chroma AT540/25x and AT605/55m) filter cubes. Images were captured through a $0.5 x$ C-mount adapter using an Optronics Microfire CCD camera and Picture Frame software.

Adobe Photoshop CS Version 4 was used to enhance images. Full-frame images of field of view equal in size and dimensions were used to create overlay images [5]. Analysis and assessment of raw integrated density values were obtained using Image J, which was also used to render 3D images.

\section{Results}

Apo $\mathrm{E}$ binds all members of the LDL receptor superfamily $[19,23,29]$. The receptor ligand sequence in Apo E spans residues ${ }^{0130} \mathrm{Thr}-\mathrm{Ala}^{0159}[30,31]$ and contains Type I and Type II ligand motifs and both types of NLS sequences (Table 1). Apo E also contains two Type III motifs, at ${ }^{071}$ Leu-Ser ${ }^{076}$ and ${ }^{091}$ Ala-Glu ${ }^{096}$ and additional NLS (Table 1). Peptide $\mathrm{E}^{0131}$-FITC, spanning $\mathrm{Glu}^{0131}$-Gly ${ }^{0173}$, contains the receptor ligand sequence LRKLRKRLLR. Synthetic peptides of the Apo E LDLR ligand region have been used to substantiate a variety of functions for this apolipoprotein [31-33], including anti-infective activity [34-36]. Lysines in this sequence are essential in binding to the LDL B/E receptors [28]. Interaction of $\mathrm{E}^{0131}$-FITC with HeLa cells was evaluated in the presence or absence of LDL. Figure 1 shows images obtained with $\mathrm{E}^{0131}$-FITC (frames (a) and (b)) and $\mathrm{E}^{0131}$-FITC plus highly purified human LDL ((c) and (d)). $\mathrm{E}^{0131}$-FITC appears to bind to the cell surface (a) and form clusters (b) but does not appear to enter the cell. In contrast, the peptide signal is seen inside the cell when LDL is added to the assay (frame (c)) as verified by quenching of fluorescence using Trypan Blue (not shown). Hence, synthetic peptides of the Apo E molecule retain cell binding properties of the intact molecule (not necessarily the capacity for internalization) and may be used to identify functional LDLR ligand motifs in DENV proteins.

The LDLR ligand motifs in Table 1 were used to identify sequences with similar function potential in DENV capsid and envelope proteins. The first $800 \mathrm{~N}$-terminal residues of the DENV polyproteins including capsid $\left({ }^{0001} \mathrm{Met}-\mathrm{Arg}^{0100}\right)$, precursor membrane protein $\left({ }^{0115} \mathrm{Phe}-\mathrm{Th}^{0280}\right)$, and envelope glycoprotein E $\left({ }^{0281}\right.$ Met-Ala $\left.{ }^{0775}\right)$ contain numerous potential receptor/GAG ligand motifs and NLS sequences (Tables 2 and 3$)$. 
TABLE 3: Receptor ligand and NLS motifs in amino-terminus of dengue virus 3 capsid protein.

\begin{tabular}{|c|c|c|c|c|c|}
\hline \multirow{2}{*}{$\begin{array}{l}\text { Capsid } \\
\text { proteins }\end{array}$} & \multicolumn{3}{|c|}{$\begin{array}{c}\text { Potential } \\
\text { receptor ligand motifs }\end{array}$} & \multicolumn{2}{|c|}{$\begin{array}{c}\text { Potential } \\
\text { nuclear localization signal }\end{array}$} \\
\hline & $\begin{array}{c}\text { ХBBBXXBX } \\
\text { (I) }\end{array}$ & $\begin{array}{l}\text { XBBXBX } \\
\text { (II) }\end{array}$ & $\begin{array}{c}\Psi \mathbf{B} \Psi \mathrm{XB} \\
(\mathrm{III})\end{array}$ & Mono & Bipartite \\
\hline $\begin{array}{l}\text { DENV3 } \\
\text { Capsid }\end{array}$ & QRKKTGKP & LKRVRN & $\begin{array}{l}\text { IKVLKG } \\
\text { LKGFKK }\end{array}$ & $\begin{array}{c}\text { RKKTGK } \\
\text { KRVRNR } \\
\text { KRFSRG } \\
\text { RGFKKE }\end{array}$ & $\begin{array}{l}\text { RKKTGKPSINMLKRVRN } \\
\text { KKEISNMLSIINKRRKT }\end{array}$ \\
\hline Dsp3CP & \multicolumn{5}{|c|}{${ }^{0002}$ NNQRKKTGKPSINMLKRVRNRVSTGSQ ${ }^{0028}$-K-FITC } \\
\hline Apo E & \multicolumn{5}{|c|}{${ }^{0142}$ RKLRKRLLRDADDLQKRLAVYQAGARE ${ }^{0168}$} \\
\hline Apo B100 & \multicolumn{5}{|c|}{${ }^{3358}$ RLTRKRGLKLATALSLSNKFVEGSHNS ${ }^{3384}$} \\
\hline
\end{tabular}

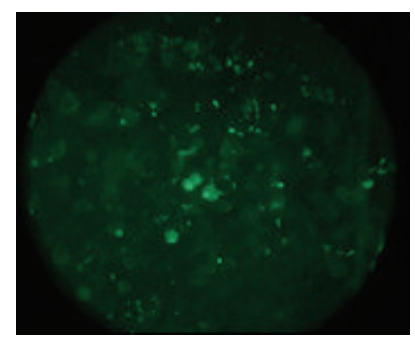

(a)

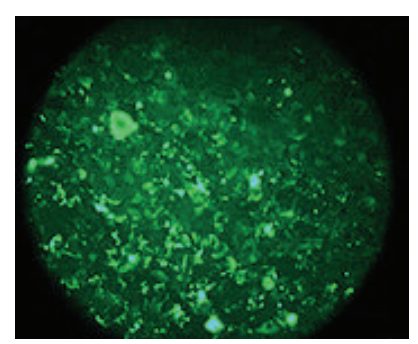

(e)

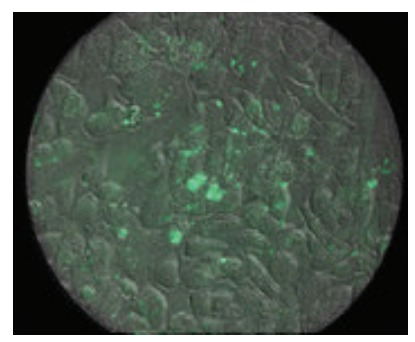

(b)

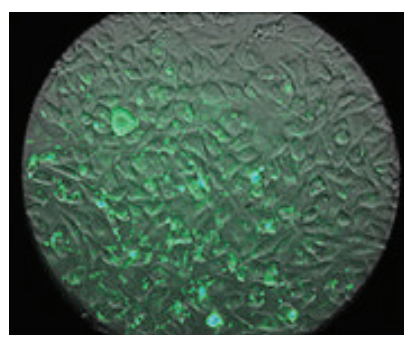

(f)

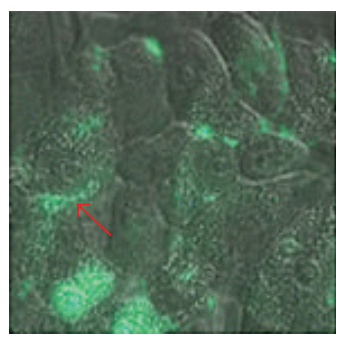

(c)

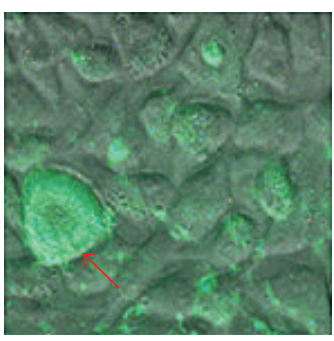

(g)

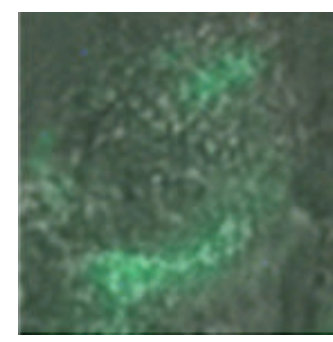

(d)

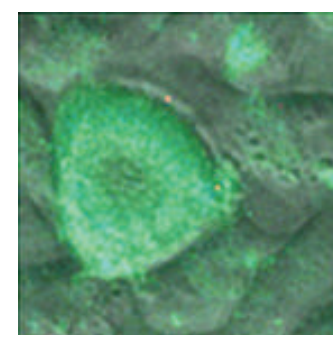

(h)

FIGURE 1: Influence of LDL on uptake of $\mathrm{E}^{0131}$-FITC by HeLa cells. An assay solution of $5 \mu \mathrm{M} \mathrm{E}^{0131}$-FITC in PBS containing $5 \mathrm{mM} \mathrm{MgCl} \mathrm{mas}_{2}$ added to HeLa cells after cultures were preconditioned overnight in medium with $3 \% \mathrm{FBS}$ and $1 \mu \mathrm{M}$ mevastatin and rinsed with $\mathrm{PBS}-\mathrm{MgCl}_{2}$. In parallel, $100 \mu \mathrm{g}$ human LDL was added to mixture. Cells were incubated for 60 minutes. Fluorescence image (a) shows binding of $\mathrm{E}^{0131}$ FITC to HeLa cells. An overlay image of frame (a) on the corresponding bright-light image is shown in frame (b). Images in frames (c) and (d) are enlargements of an area in (b) and show $\mathrm{E}^{0131}$-FITC as clusters on the cell surface. Binding of $\mathrm{E}^{0131}$-FITC in the presence of unlabeled LDL is shown in frame (e) with the corresponding overlay in frame (f). Images in frames ( $g$ ) and (h) are enlargements of a region in frame (f) and show that fluorescence is present in the cytoplasm.

3.1. Dengue Virus 2 Envelope Glycoprotein. Peptide Dsp2-EP with two ligand motifs, $\Psi \mathbf{B} \Psi \mathrm{XBX}$, and one NLS sequence, XBXBXBX (Table 2), was evaluated for cell binding capacity. A comparison of similar motifs present in Apo E and Apo B200 is included in Table 2. Only Type III ligand motifs are present in DENV envelope protein (E protein) sequences that are rich in Glycine, Lysine, and Arginine residues, approximately $10 \%, 7 \%$, and $3 \%$, respectively. Figure 2 images (A1)-(A4) show that Dsp2EP-FITC binds HeLa cells but does not appear in the cytoplasm. Images (A2) and (A4), enlarged areas of (A1) and a similar field of view, clearly demonstrate the appearance of clusters on the cell surface. Mutated synthetic peptides Dsp2EP (B)- and (C)-FITC in which Aspartates replace basic residues in one of the ligand motifs (Table 2) also bind cells and do not appear in cytoplasm.
Images (A3), (B3), and (C3) show that addition of Trypan Blue dye quenches fluorescence and confirms that Dsp2EP and mutated forms bind to the cell surface but lack cell entry capacity. Raw integrated densities for images (A1), (B1), and (C1) obtained using Image J are shown in Figure 2(b). Reduced integrated densities are observed for the mutated peptides indicating that each ligand motif may be functional but not as efficient in binding as their combination in Dsp2EP.

HeLa cells were used to test cell binding properties of Dsp2EP-FITC in presence of Apo E and LDL. Increasing amounts of unlabeled Apo E were included with $10 \mu \mathrm{g}$ Dsp2EP-FITC in $500 \mu \mathrm{L} \mathrm{PBS} / 5 \mathrm{mM} \mathrm{MgCl}_{2}$ and placed at $4^{\circ} \mathrm{C}$ for 18 hours. In parallel, unlabeled human LDL was added to HeLa cells and similarly incubated. Overlays of bright-light and fluorescence images are shown in the lower 


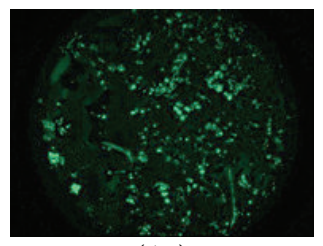

(A1)

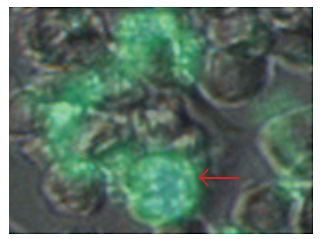

(A2)

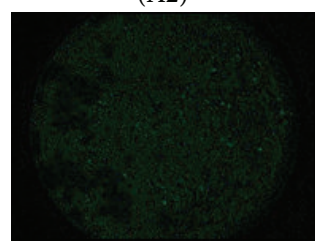

(A3)

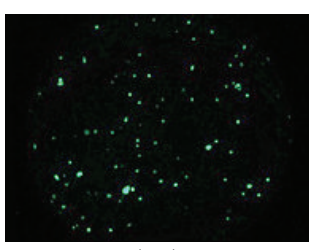

(B1)

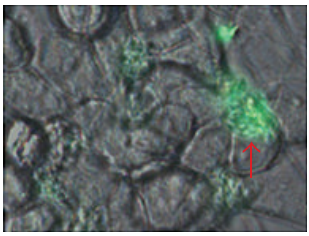

(B2)

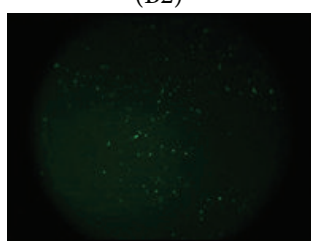

(B3)

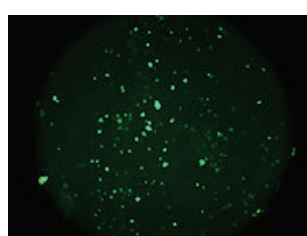

(C1)

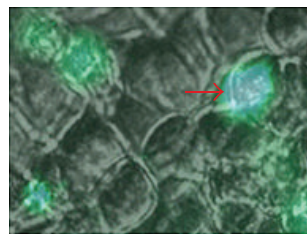

(C2)

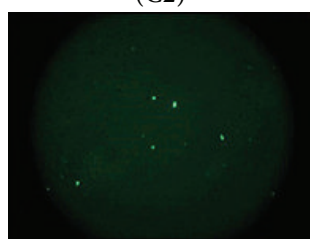

(C3)

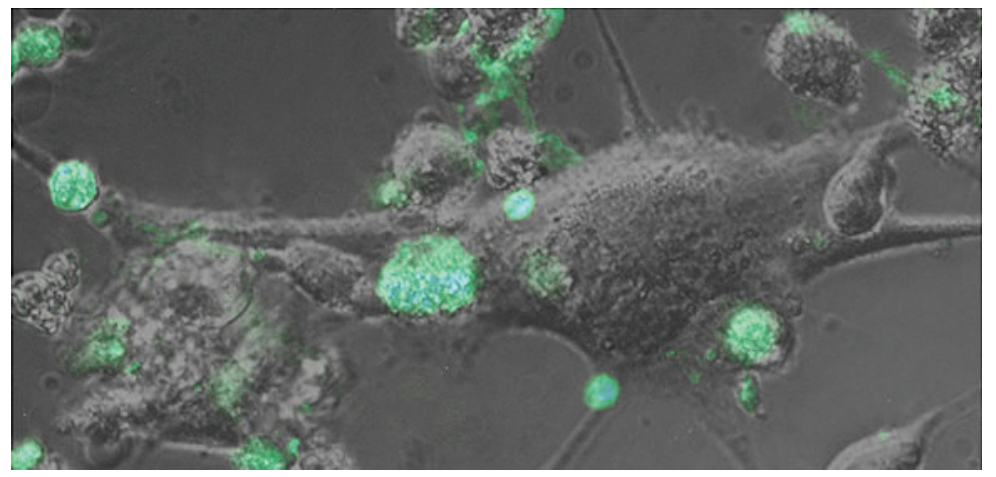

(A4)

(a)

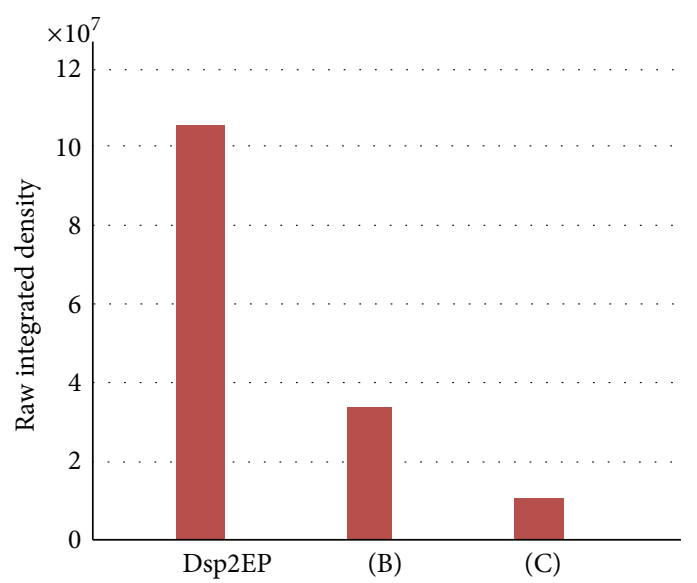

(b)

FIGURE 2: HeLa cell binding of Dsp2EP-FITC compared to mutated peptides Dsp2EP (B)-FITC and Dsp2EP(C)-FITC. Briefly, 1 mg of peptide was solubilized in $1 \mathrm{~mL}$ PBS and $\mathrm{MgCl}_{2}$ in microfuge vials. Each was centrifuged to clarity and $30 \mu \mathrm{L}$ of the solution was added to cells. (a) Images in frames (A1), (B1), and (C1) show green fluorescence of Dsp2EP, Dsp2EP (B), and Dsp2EP (C), respectively, bound to cells. Overlays (A2), (B2), and (C2) are enlarged regions of (A1), (B1), and (C1) with their corresponding bright field images. Red arrows indicate loci that suggest clustering of labeled peptide. Images (A3), (B3), and (C3), repeat cultures of those in top row, show fluorescence quenched using Trypan Blue dye. Enlarged overlay in frame (A4) shows that Dsp2EP-FITC appears in clusters on the cell surface. (b) Comparison of raw integrated densities for images (A1), (B1), and (C1). Results were normalized based on absorbance at $494 \mathrm{~nm}$. Results illustrate the importance of both RXXK and KXXK motifs in cell binding. 


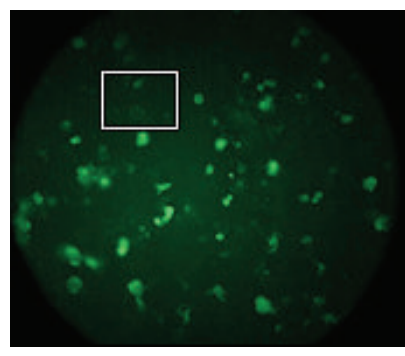

(A)

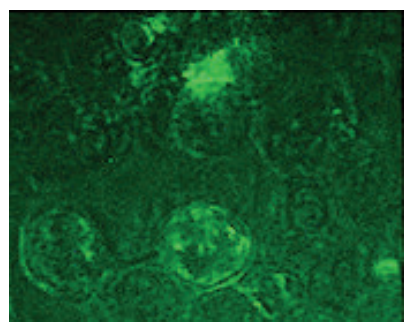

(A1)

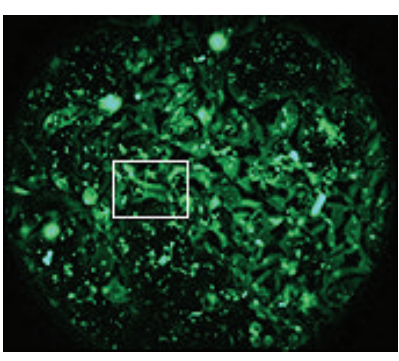

(B)

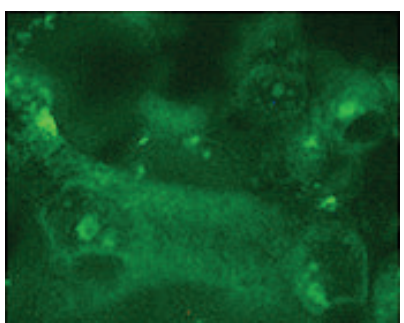

(B1)

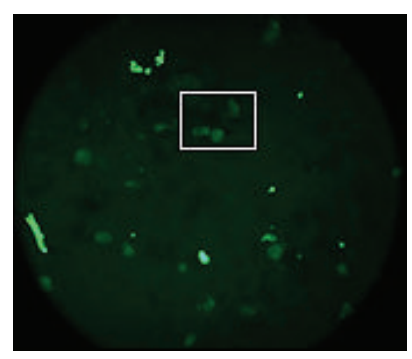

(C)

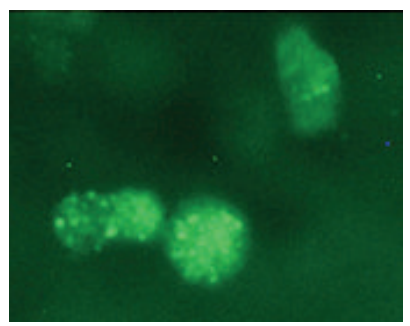

(C1)

(a)

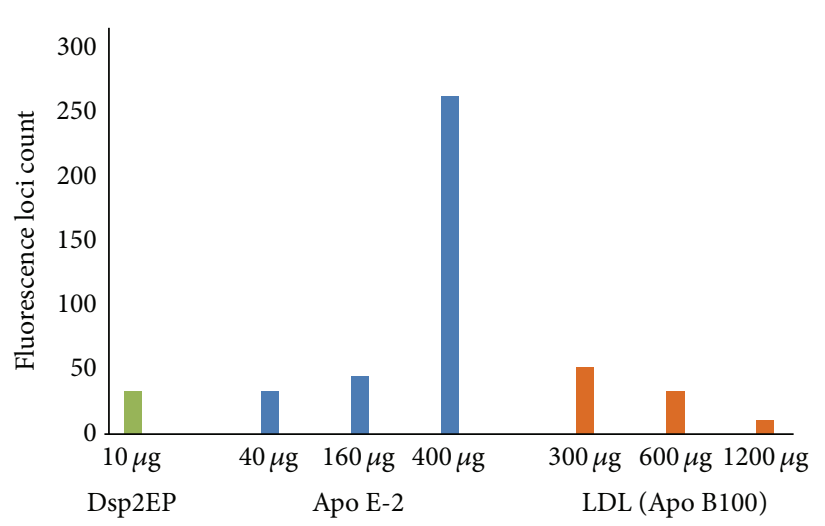

(b)

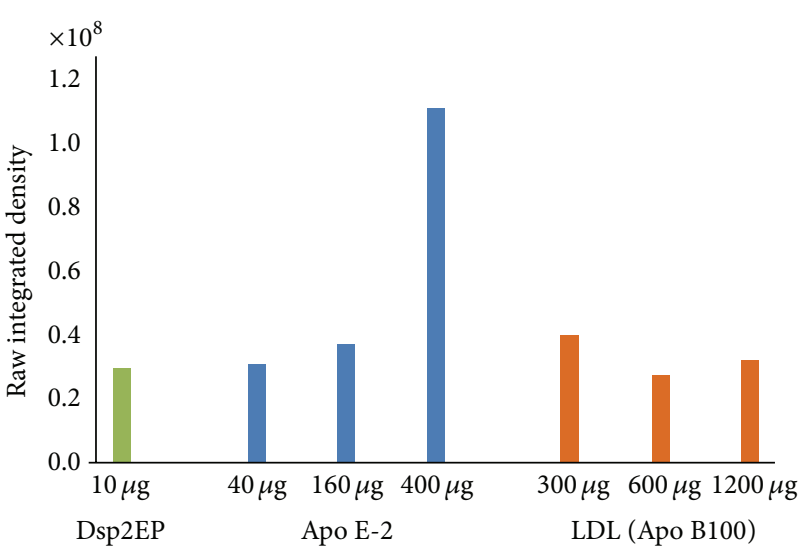

(c)

Figure 3: Effects of peptide E-2 and LDL on HeLa cell binding of Dsp2EP-FITC. (a) Unlabeled E-2 (40 $\mu \mathrm{g}, 160 \mu \mathrm{g}$, and $400 \mu \mathrm{g})$ was added to each culture containing $10 \mu \mathrm{g}$ Dsp2EP in $500 \mu \mathrm{L}$ PBS- $5 \mathrm{mM} \mathrm{MgCl}_{2}$ and placed at $37^{\circ} \mathrm{C}$ for 18 hours. Parallel assays were performed using unlabeled human LDL (300 $\mu \mathrm{g}, 600 \mu \mathrm{g}$, and $1200 \mu \mathrm{g})$ in lieu of E-2. Representative images obtained for experiments Dsp2EP-FITC alone, plus peptide E-2, and plus LDL are shown in frames (A), (B), and (C), respectively. Enlarged images (A1), (B1), and (C1) are of areas indicated in corresponding frames and show fluorescence signal in clusters on the cell surface. (b) Number of points (loci) of signal for images in frames (A), (B), and (C) of Figure 3(a). (c) total raw integrated densities for the same frames (A), (B), and (C) in Figure 3(a). Image J software was used to count loci and integrate the fluorescence signal. The number of fluorescing loci and integrated density values for cells treated with $10 \mu \mathrm{g}$ Dsp2EP-FITC alone are shown in green columns, Dsp2EP-FITC plus unlabeled E-2 peptide is in blue, and Dsp2EP-FITC plus unlabeled purified human LDL are in orange. Amounts of E-2 peptide or LDL used in the assays are shown under each column. E-2 peptide at high concentration significantly enhances binding of Dsp2EP-FITC to HeLa cells which appears to be ubiquitous, frame (B) in Figure 3(a).

section of Figure 3. Image (A) shows fluorescence obtained for $10 \mu \mathrm{g}$ Dsp2EP-FITC (positive control). Images (B) and (C) were obtained with cultures containing $10 \mu \mathrm{g}$ Dsp2EP-FITC in presence $400 \mu \mathrm{g}$ of unlabeled Apo E (B) and $300 \mu \mathrm{g}$ of unlabeled LDL (C) in the assay. Enlarged areas in (A1), (B1), and $(\mathrm{Cl})$, respectively, show that fluorescence appears both diffused on the cell surface and in clusters.

Graph in Figure 3(b) shows the number of loci of Dsp2EP-FITC bound to HeLa cells in presence of unlabeled Apo E-2 peptide and LDL $(10 \mu \mathrm{g}$ of the peptide in all wells; effects of $40 \mu \mathrm{g}, 160 \mu \mathrm{g}, 400 \mu \mathrm{g}$ of Apo E-2, and $300 \mu \mathrm{g}$, $600 \mu \mathrm{g}, 1200 \mu \mathrm{g}$ of LDL). Addition of unlabeled Apo E-2 peptide enhances Dsp2EP binding significantly as is shown by the increase in the number of loci with fluorescence (Graph (b), blue columns) and the increase in total raw integrated density (Graph (c), blue columns). Also, results in image (B), Figure 3(a), indicate that addition of Apo E2 makes receptors available almost ubiquitously across the field of view. In comparison, the presence of LDL reduces the number of Dsp2EP-FITC fluorescing loci as shown in image (C) and Graph (b) (orange columns). These data also indicate that receptors for the Dsp2EP-FITC are made available in a limited number of cells. Our observations suggest a mechanism in which increased concentration of 
Apo E-2 triggers a conformational change in the receptor making more binding modules available for Dsp2EP-FITC binding, a mechanism reported previously for LDL receptors $[23,37,38]$.

Dual label experiments using Dsp2EP-FITC with either Apo E-CM-DiI or LDL-CM-DiI, as described in Section 2, were performed to assess colocalization of Dsp2EP-FITC with Apo E and LDL. Images were obtained as described above. Overlay in frame (A) of Figure 4 shows combined fluorescence of Dsp2EP-FITC and Apo E-CM-DiI. Enlarged representative regions showing green, red, and yellow signals are indicated by $1-8$. Each image was subjected to digital analysis using Image $J$ and split into channels red, blue, and green, and raw integrated densities were then rendered in 3D. Enlarged images 1, 2, 5, and 6 are shown at bottom two rows of Figure 4 as 1G, 1R, and so forth. 3D images reveal that Dsp2EP-FITC binds solo as well as colocalized within the red clusters formed by Apo E-CM-DiI. These observations suggest that Dsp2EP-FITC and Apo E-CM-DiI may share receptors, binding to either the same or adjacent receptor molecules. Apo E-CM-DiI signal appears uniformly in clusters with similar maxima in all enlarged images, $1 \mathrm{R}$, $2 R, 5 R$, and $6 R$, in Figure 4. This may indicate saturation in the area density of receptors occupied by Apo E, which is consistent with the finding that each LDLR provides two modules for Apo E binding [38]. This mechanism may leave sufficient number of unoccupied modules for binding to other ligands, such as Dsp2EP-FITC.

Results of parallel dual label experiments using Dsp2EPFITC and LDL-CM-DiI are shown in Figure 5. A section of an overlay image presented in frame (A) shows separate loci of LDL-CM-DiI and Dsp2EP-FITC, respectively, while a yellow signal indicates colocation. Areas 1, 2, and 3 in frame (A) are shown enlarged as images 1,2 , and 3 in the row beneath. Image 1 shows loci of Dsp2EP-FITC alone and collocated with LDL-CM-DiI, as pinkish and yellow signals (also evident in $1 \mathrm{G}$ and $1 \mathrm{R})$. Image 2 shows loci indicating LDL-CM-DiI predominantly (2R) except for two green dots identified as Dsp2EP-FITC (2G). Image 3 suggests a stronger presence of Dsp2EP-FITC versus LDL-CM-DiI that is supported by 3R and 3G. LDL-CM-DiI appears to form clusters similar to those seen for Apo E-CM-DiI discussed above. These results suggest that in some regions of the cell surface Dsp2EP-FITC may interact with the same receptor molecules as do Apo E and LDL.

3.2. Dengue Virus 3 Capsid Protein. The DENV nucleocapsid, encasing the viral genome, is enclosed by the bilayer lipid membrane in which the envelope glycoprotein is anchored [1]. The nucleocapsid is comprised of multiple molecules of the capsid protein (C protein) associated with lipid. In DENV capsid proteins (residues 0001-0100 of the viral polyprotein), basic amino acids $\mathrm{K}$ and $\mathrm{R}$ represent approximately $26 \%$ of the sequence and are present in approximately equimolar concentrations. Ligand motifs, I, II, and III, are abundant (Table 3) and may impart the capsid protein with multiple options in binding to both receptor proteins and glycosaminoglycans. Such binding capacities may be functionally significant (see Section 4). Type I ligand motifs are present in DENV1, 3, and 4 C proteins, motif Types II and III occur in the capsids of all four viral versions; there is also a surplus of potential mono- and bipartite NLS.

Dsp3CP-FITC ( ${ }^{0002}$ Asn-Gln ${ }^{0028}$ of the DENV3 capsid protein, Table 3) contains a type I, QRKKTGKP, and a type II, LKRVRNR motifs (Table 3), that may function as monopartite and as components of a bipartite NLS. Dsp3CP-FITC was tested for cell entry and nuclear translocation potential in mevastatin-treated HeLa cells. Results are shown in Figure 6, (A1) and (A2) (an enlarged area of (A1)). Fluorescence appears located in cytoplasm in apparent endosomes, and clusters are seen in the nuclear space. This distribution of fluorescence is seen in most images obtained with Dsp3CPFITC. Similar patterns were observed in presence of increasing concentrations of unlabeled Apo E-2. Examples are shown in Figure 6 (B1), with an enlarged area in (B2), which shows Dsp3CP-FITC signal in loci suggesting endosomes, at loci proximal to the nuclear envelope, and possibly in the nuclear space. Hence, Apo E-2 peptide at 1.5 molar excess does not appear to influence cell entry or nuclear translocation of Dsp3CP-FITC.

In dual label experiments, Apo E-CM-DiI was added with Dsp3CP-FITC to live HeLa cells in FBS-depleted EMEM and then incubated at ambient temperature for 15 and 90 minutes. Results are shown as overlays in Figure 6 rows (C) and (D), respectively. At 15 minutes (row (C)), colocalized signals are evident across the field of view with most appearing at the cell surface. This observation suggests a sharing of receptors and/or clustering of receptors carrying different signals. Enlarged overlay (C)1 shows a cell with colocalized signals at the membrane, in the cytoplasmic space, and apparently in the nuclear space. Enlarged overlays (C) 2 and (C) 3 show colocalized signals at discrete loci on cell surface. Dsp3CPFITC represents $\sim 71 \%$ raw integrated density; this includes diffused green, whitish green clusters indicating colocalized signals in the cytoplasm, and possibly in the nuclei. At the 90 minute point (row (D)), intracellular separation of Dsp3CPFITC and Apo E-CM-DiI is evident. Dsp3CP-FITC signal appears both at discrete loci and diffused in cytoplasm. Elevated green fluorescence background may indicate binding of Dsp3CP-FITC to extracellular debris on culture plate. In overlays (D)1-(D)3 Apo E-CM-DiI is clearly separated from the diffused Dsp3CP-FITC; red signal seems to fill the nuclear space, where colocalization of the two signals is also apparent (yellow dots). These results in toto suggest Dsp3CP-FITC, which contains receptor ligand motifs and NLS sequences, may share LDL B/E receptors in cell entry and then translocate to nucleus.

\section{Discussion}

Humans, sylvatic nonhuman primates, and mosquitoes are major reservoirs of DENV and other Flaviviridae [7]. LDLR and/or LRPs are expressed in most cell types in humans. Analogue proteins in Aedes aegypti [39-41] and Culex quinquefasciatus [42] include apolipophorins and lipophorin 


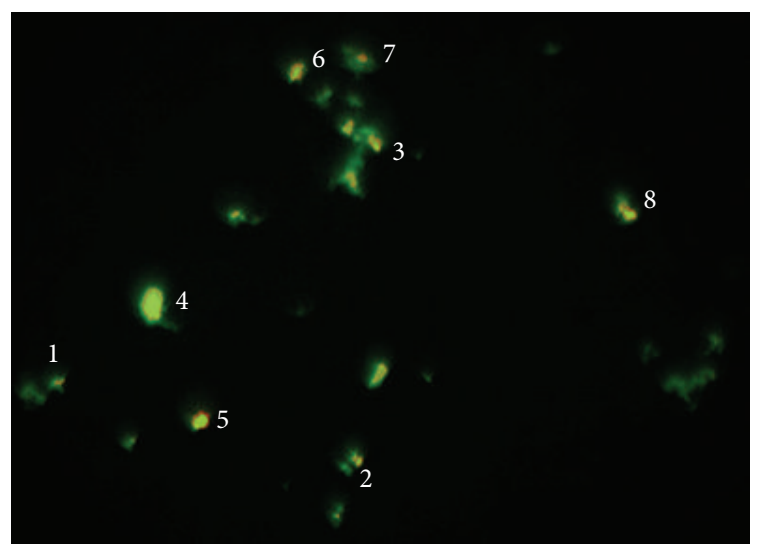

(A)
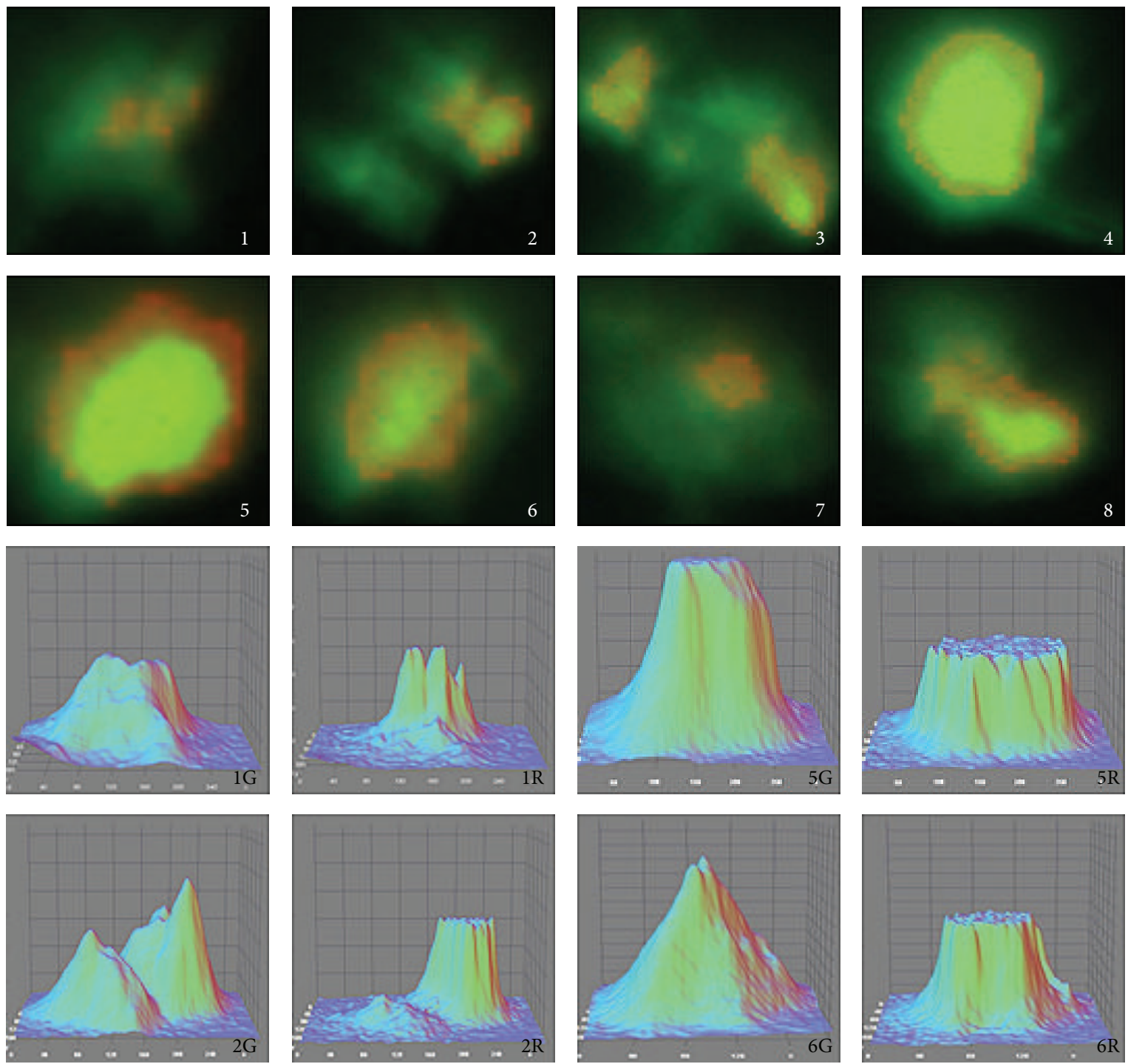

Figure 4: Dual label HeLa cell binding experiments using Dsp2EP-FITC and Apo E-CM-DiI. Overlay of Dsp2EP-FITC (green fluorescence) and Apo E-CM-DiI (red fluorescence), frame (A), shows colocalized signals in yellow. Images of areas labeled 1-8 of the overlay image were enlarged in Photoshop then analyzed with Image J. Image 1 shows diffused signal for Dsp2EP-FITC (green) with clusters of red signal indicating Apo E-CM-DiI. Images in frames 1-8 reveal a consistent pattern, that is, diffused (spread) binding of Dsp2EP-FITC and clustering of Apo E-CM-DiI. Red and green colors were separated using Image J and then rendered using Interactive 3D Surface Plot Plugin algorithm. Images $1 \mathrm{G}$ and $1 \mathrm{R}$ represent green and red signals, respectively. Images $1 \mathrm{R}, 2 \mathrm{R}, 5 \mathrm{R}$, and $6 \mathrm{R}$ represent Apo E-CM-DiI and show formation of clusters of similar intensity. Corresponding green signal images show less uniformity. 


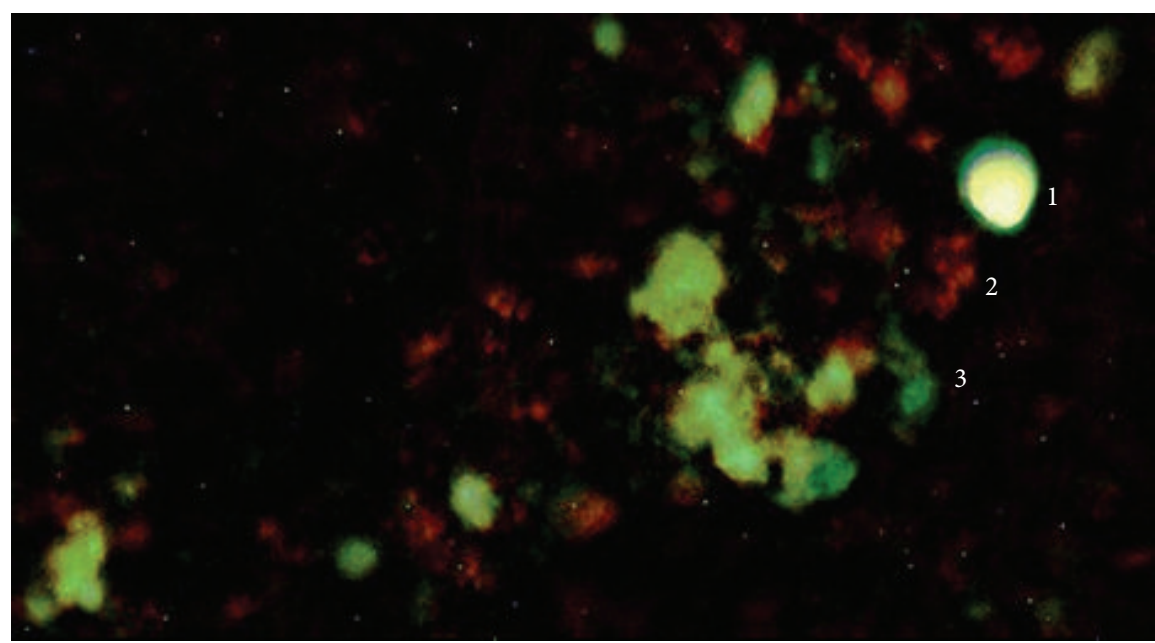

(A)
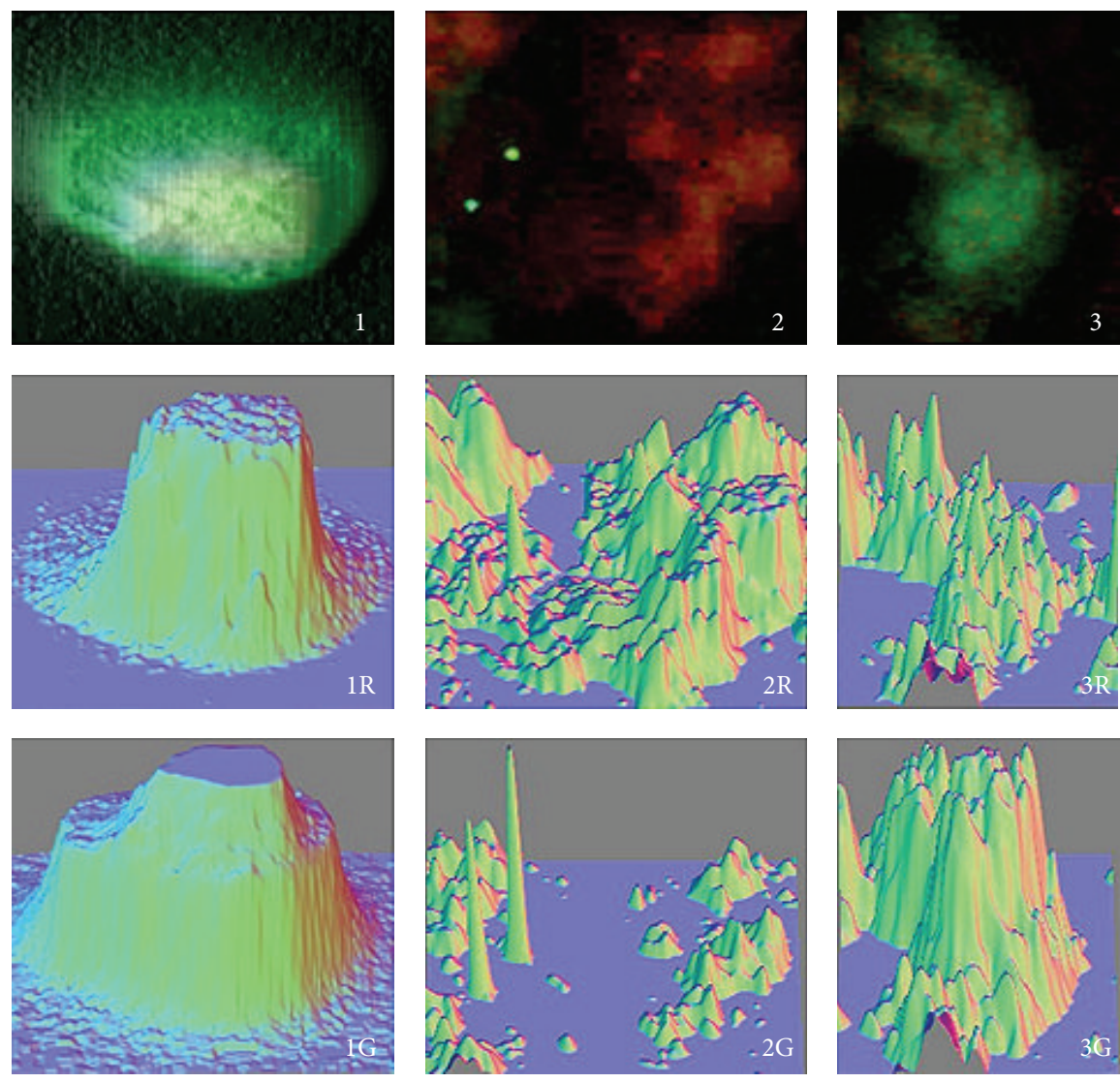

Figure 5: Dual label HeLa cell binding experiments using Dsp2EP-FITC and LDL-CM-DiI. Overlay (A) shows images of Dsp2EP-FITC (green) and LDL-CM-DiI (red) fluorescence images. Loci 1, 2, and 3 indicated in frame (A) are shown as enlarge images in frames 1, 2, and 3 , respectively. Signals in locus frame 1 appear in three distinct colors, yellow, pink, and green. Red is the predominant signal in locus (A)2, frame 2, while green signal is seen in locus (A)3, frame 3. Image J was used to separate green and red signals, rendered in 3D in corresponding frames $1 R$ and $1 G, 2 R$ and $2 G$, and $3 R$ and $3 G$, respectively.

receptor [43-46]. There are 17 different known members in the LDL receptor gene family (LRPs) including LDLR, VLDLR, LRPs 1-6, 8, 10, 11, and 12, Megalin (LRP2), and ST7p. All members have five distinct structural components, three are extracellular, one transmembrane sequence, and a cytoplasmic, carboxyl region [47]. Relevant to the present report are the numerous clusters of ligand-binding, cysteinerich modules contained in the extracellular domain (also 


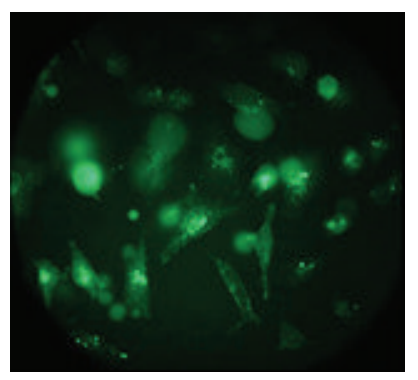

(A1)

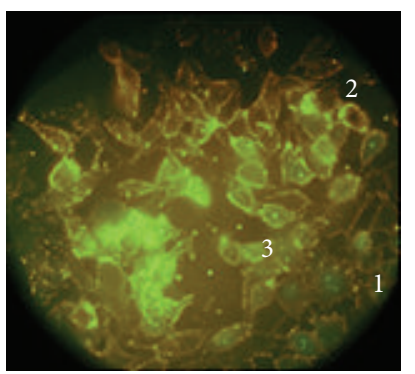

(C)

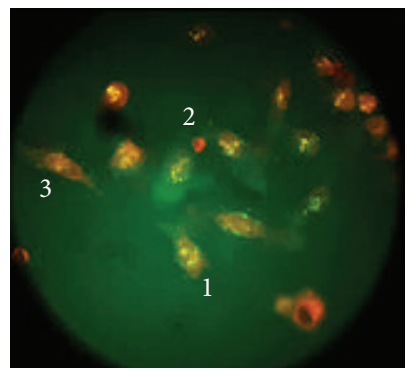

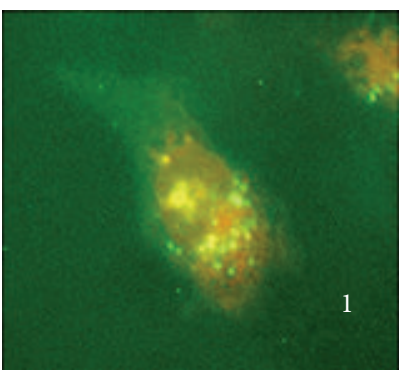

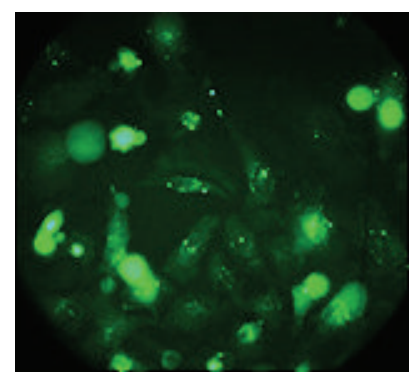

(B1)
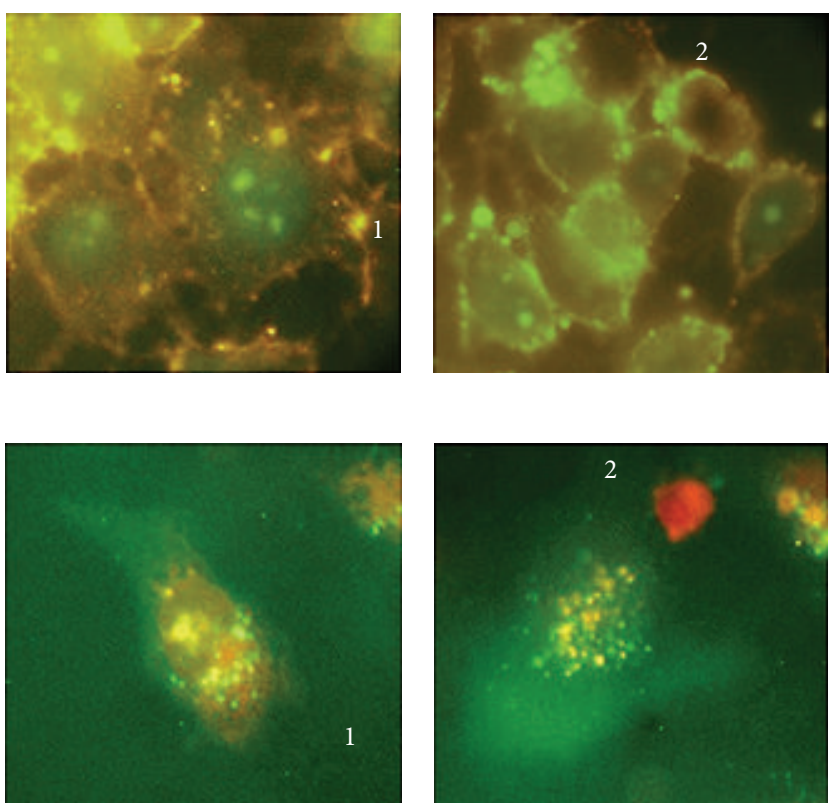

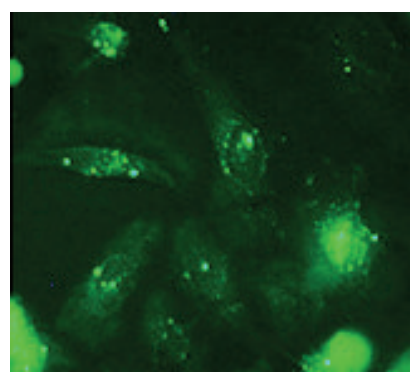

(B2)
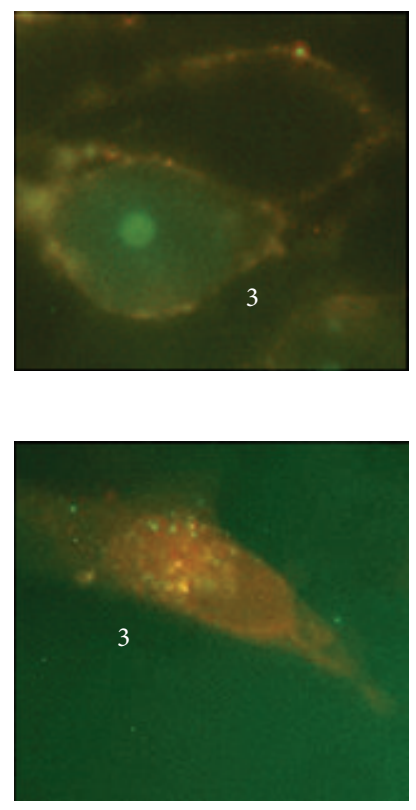

(D)

FIGURE 6: HeLa cell entry and nuclear translocation of Dsp3CP-FITC. Image in frame (A1) shows cell uptake and nuclear translocation of Dsp3CP-FITC alone. Image (A2), an enlarged region of (A1), shows fluorescence suggestive of endosome-like structures and clusters in and about the nuclear space. Image (B2) shows location of Dsp3CP-FITC signal in the presence of Apo E-2 peptide. Image (B2), an enlarged region of (B1), also shows evidence that Dsp3CP-FITC signal occurs in endosomes and the nuclear space apparently unaffected by the addition of unlabeled Apo E-2 at 1.5 molar excess. Images in rows (C) and (D) were obtained in dual label experiments using $24 \mu \mathrm{L}$ of Dsp3CP-FITC $(50 \mu \mathrm{g})$ and Apo E-CM-DiI $(75 \mu \mathrm{g})$ mix. Apo E-CM-DiI-and Dsp3CP-FITC were added to live HeLa cells in FBS-depleted EMEM then incubated at ambient temperature for 15 and 90 minutes, (C) and (D) series, respectively. Areas 1, 2, and 3 in image (C) are enlarged to show typical colocalized signals on the cell membrane. Green signal also clearly appears in the nucleus at this early time point. In (D), signals appear separate as well as colocalized within the cell perimeter. Interestingly, FITC signal appears to be dispersed both within the cell and in the extracellular space while Apo E CM-DiI signal is indicated mostly within the cells. Cell nuclei appear to contain both green and red label.

known as complement-like repeats and ligand adhesion type A units). There are a total of 170 known renditions of ligandbinding modules that recognize at least 30 different ligands belonging to a variety of protein families. All LRPs are thought to bind Apo E [47].

DENVs are known to employ multiple mechanisms to obtain cell entry $[11,48]$. There is evidence that DENV interacts initially with heparan sulfate proteoglycans essential in anchoring at the cell surface [49, 50]. Several target proteins on the cell surface have been identified and clathrinmediated endocytosis has been shown to play role in DENV internalization in both mammalian and insect cells $[48,51-$ 53]. It is possible that viruses have evolved to use abundant
LDL and LRP receptors to gain ubiquitous access to human tissues. These receptors provide classical examples for the cargo internalization via clathrin-mediated endocytosis; they are also glycosylated and hence may provide GAG-mediated initial attachment of the virion which facilitates specific interaction with the receptor.

DENVs are known to infect a variety of tissues [54] in vivo and numerous human cell types in vitro including epithelial cells [55] and HeLa cells [56]. Dendritic cells (DCs) and macrophages are the primary targets for DENV infection in human blood $[57,58]$. Permissive monocytes, antigen presenting cells, ingest and process the viral particle prior to presenting its components, proteins and nucleic 
TABLE 4

\begin{tabular}{|c|c|c|c|}
\hline \multirow{3}{*}{ Envelope proteins } & \multirow{2}{*}{\multicolumn{2}{|c|}{$\begin{array}{c}\text { Potential } \\
\text { receptor ligand motifs }\end{array}$}} & \multirow{3}{*}{$\begin{array}{c}\text { Potential } \\
\text { nuclear localization signal } \\
\text { Bipartite }\end{array}$} \\
\hline & & & \\
\hline & $\Psi \mathbf{B} \Psi \mathbf{X B} \quad$-loop- & $\Psi \mathbf{B} \Psi X \mathbf{B}$ & \\
\hline DENV1 & \multicolumn{2}{|c|}{${ }^{0563}$ LKCRLKMDKLTLKGVSYVMCTGSFKLEKEV ${ }^{0592}$} & ${ }^{0673}$ KKGSSIGKMFEATARGARR \\
\hline DENV2 & \multicolumn{2}{|c|}{${ }^{0563}$ LKCRLRMDKLQLKGMSYSMCTGKFKIVKEI I592 } & ${ }^{0673}$ KKGSSIGQMFETTMRGAKR \\
\hline DENV3 & \multicolumn{2}{|c|}{${ }^{0561}$ LKCRLKMDKLELKGMSYAMCTNTFVLKKEV ${ }^{0590}$} & ${ }^{0671}$ KKGSSIGKMFEATARGARR \\
\hline DENV4 & \multicolumn{2}{|c|}{${ }^{0558}{ }^{2 K C K V R M E K L R I K G I S Y T M C S G K F S I D K E M ~}{ }^{0587}$} & ${ }^{0668}$ RKGSSIGKMFESTYRGAKR \\
\hline
\end{tabular}

DENV1, BAD42414.1; DENV2, ACY70846.1; DENV3, ADI80662.1; DENV4, AAW51421.1.

acid, to immune response cells, T-cells, in the lymph nodes $[59,60]$. In DCs, dengue viruses are recognized by a Ctype lectin, DC-specific intercellular adhesion molecule-3 grabbing nonintegrin (DC-SIGN) [57, 58]. DC-SIGN also recognizes the arenavirus Lassa virus [61] and the Enterovirus $71[62]$.

When the mosquito injects its beveled stinger (proboscis) into the epidermis it deposits a mixture of salivary proteins along with the DENV particles. Keratinocytes that can express the LDLR [63] and LRPla [64] and make up 95\% of the epidermis may represent the first line of defense against arboviruses. Only a small fraction of the DENV injected by the mosquito enters the blood compartment and is addressed by the dendritic cells [59]. The rest may remain with the tissues at the injection site where the keratinocytes stimulate inflammation and activate Langerhans cells [65]. By comparison, only chemically modified forms of LDL, for example, oxidized-LDL, are engulfed and removed from the blood by DC-scavenger receptors [66]; native LDL is removed from circulation by various tissues expressing LDLR and LRPs.

The hypothesis of DENV specific interaction to LDL or related receptor is strongly supported by sequence comparison of viral proteins to known LDLR/LRP ligands. In the Apo E receptor ligand site $\left({ }^{0130} \mathrm{Thr}-\mathrm{Ala}^{0159}\right.$; PDB: 1LPE), Lysine residues in positions 0143 and $0146,{ }^{0141}$ LRKLRKRLLR ${ }^{0150}$, are essential for binding LDL B/E receptors [28] and Arginine residues located between ${ }^{0170} \mathrm{Ala}-\mathrm{Leu}^{0181}$ are involved in binding GAGs and heparan sulfate proteoglycans, HSPGs [24]. Our examination of the DENV polyprotein sequences revealed that potential ligand analogues occur in structural as well as in nonstructural proteins. In DENV, the envelope glycoproteins that span residues ${ }^{0281}$ Met-Ala ${ }^{0775}$ make the initial contact with receptor molecules on the cell surface [67]. We posited that this interaction involves the LDLR Lysine/Arginine-rich ligand motifs contained in the DENV envelope and capsid proteins.

In DENV envelope proteins, the region essential for cell entry, Domain III, spans ${ }^{0580} \operatorname{Ser}-\operatorname{Trp}{ }^{0671}$ [68]. Studies by Falconar [69] showed that a neutralizing monoclonal 3A8.1 has a high binding avidity for several DENV2 E proteinderived peptides, including ${ }^{0568} \underline{\mathbf{R M D K L Q L K G}}{ }^{0576}$ and ${ }^{0584}$ GKFKIVKEI $^{0592}$ located in $\mathrm{E}$ protein Domains I and III, respectively [70]. Both peptides contain LDLR Type III ligand motifs (Table 1); analogues are present as ${ }^{0567}$ LKMDKL in DENV1 and 3, as ${ }^{0567} \mathrm{~L} / \mathrm{VRMD} / \mathrm{EKL}^{0572}$ in
DENV2 and DENV4, and as ${ }^{0586} \mathrm{FKLE} / \mathrm{VKE}^{0591}$ in DENV1 and 2 (Table 4). The latter motif is absent in DENV3 and 4. Instead, DENV4 E protein has an analogue of the motif as ${ }^{0478}{ }^{2 M K M K K K T}{ }^{0485}$. In the PBD model 1OAN of the DENV2, both motifs in tandem appear in a loop located on the surface of the molecule.

We used fluorescence-labeled synthetic peptides of DENV sequences containing LDLR/LRP ligand motifs in dual label experiments with Apo E CM-DiI and LDL CM-DiI. This approach presents advantages over using an intact virus including cost issues, safety issues, and steric hindrance. As illustrated in Results, our Dsp2EPFITC peptide that spans DENV2 region ${ }^{0564}{ }^{2 y s}-{ }^{0595}$ and contains the two Type III ligand motifs binds HeLa cells but is not internalized. Dsp2EP-FITC also binds HepG2 cells (shown as a Supplemental Figure 1 available online at http://dx.doi.org/10.1155/2015/646303). Dsp2EP-FITC (B) and $(C)$, mutated forms of Dsp2EP-FITC, bind HeLa cells with lower integrated density (Figure 2(b)). Similar binding pattern (decreased binding of the mutated peptides compared to the nonmodified version) was observed with dextran sulfate cellulose beads (Supplemental Figure 2). These results confirm that residues $\operatorname{Arg}^{0568}$ Lys $^{0571}$, Lys $^{0587}$ and Lys ${ }^{0590}$ in LDLR ligand motifs play a role in binding to the cell surface. Colocalization of Apo E-CM-DiI and Dsp2EP-FITC suggests that they may bind the same receptor or adjacent molecules. The LDL receptor contains 7 copies of the ligand modules, and Apo E binds only LA4 and 5 modules [38]. Hence, presence of Apo E-FITC may not hinder binding of Dsp2EP-FITC to the remaining modules and would result in colocalized red and green signals. Further, involvement of other LRPs should not be ruled out.

Sequence similarities exhibited by human Apo E, Apo $B$, and DENV capsid proteins were first described in our earlier report [5]. The 3D models of Apo E [27] and DENV2 capsid protein [26] show that both are helix-loop/turn-helix molecules with amphipathic features that encourage homodimerization in a pure state and perhaps heterodimerization in a mixture. These common properties may account for DENV capsid protein specific interaction with VLDL [71]. All three proteins associate with lipids, bind nucleic acids, possess cell entry capacity, and translocate to the cell nucleus.

The primary structures of DENV capsid proteins suggest them to be multifunctional proteins with analogues of LDLR and LRP ligand and NLS motifs at both termini $[72,73]$. Based on our studies, DENV3 capsid may have inherent 
cell entry capacity. LRP ligand analogues occur within the first 40 residues of the $\mathrm{N}$-termini of DENV capsid proteins. In DENV3 capsid protein two ligand motifs, RKKTGK and LKRVRN, two mono-NLS ( ${ }^{0005}$ Arg-Lys ${ }^{0010},{ }^{0017}$ Lys-Arg $^{0020}$ ), and one bi-NLS ( ${ }^{0006}$ Lys-Arg ${ }^{0020}$ ) motifs likely provide the capsid not only with cell entry capacity but also with potential to transit into the nucleus. DENV2 $\mathrm{C}$ protein, Type II ligand analogue, ${ }^{0004} \mathrm{QR} \underline{\mathbf{K} K A} \underline{\mathbf{K}} \mathrm{N}^{0010}$, is also a high affinity LRP ligand. DENV1 and $4 \mathrm{C}$ proteins, ${ }^{0004}$ QRKKTGRP ${ }^{0011}$ and ${ }^{0003} \mathrm{QRKKVVRP} \mathrm{P}^{0010}$, respectively, are Type I ligand motifs and may impart both LRP/GAG binding and nuclear translocation potentials. Our results and those reported by others [74] support the premise that the intact DENV capsids have inherent infectivity capacity and may be an important player in the second phase of the DENV infection process as an unfinished/immature viral particle.

Considering that LDLR/LRP receptors occur ubiquitously in humans, sylvatic mammals, and mosquitoes, Aedes sp. and Culex sp., and that the receptor ligand motifs are mimicked by DENVs [75], it is possible that DENV possesses a "pass" into virtually any human cell type. Then vascular leakage of the virus in DHF syndrome [76] could lead to infection of vital organs such as liver, spleen, lungs, heart, and kidneys. High level of infectivity provided by the LDLR/LRP mechanism may be a major factor in dengue shock syndrome and dengue hemorrhagic fever.

\section{Conclusion}

We conclude that dengue viruses may have the capacity to achieve cell binding and entry via the receptors utilized by low density lipoproteins. Our results indicate that dengue capsid and envelope proteins contain Lysine-based LDL receptor ligand and NLS motifs. Synthetic peptides of DENV proteins, representing potential LDL receptor binding sites, colocalize with LDL and Apo E on the cell surface. In humans and other mammals LDL receptors are expressed ubiquitously throughout the organism, a factor that may greatly enhance viral infectivity. The processes for cell entry for dengue virus have not been fully elaborated, and our report provides an additional intriguing possibility for molecular mechanisms of viral entry.

\section{Abbreviations}

CP: $\quad$ C protein, capsid protein

Cm-DiI: Cell Tracker C7000

DENV: Dengue virus

EP: $\quad$ E protein, envelope protein

FITC: Fluorescein isothiocyanate

GAGs: Glycosaminoglycans

HSPG: Heparin sulfate proteoglycan

IDL: Intermediate density lipoprotein

LDL: Low density lipoprotein

LDLR: Low density lipoprotein receptor

LLP(s): Low density lipoprotein particle(s)

NLS: Nuclear localization signal

VLDL: Very low density lipoprotein.

\section{Conflict of Interests}

The authors declare that there is no conflict of interests regarding the publication of this paper.

\section{Acknowledgments}

Studies were supported in part by Grants F49620-99-1-0327 (AFOSR, PI, Juan Guevara Jr.), FA 9550-05-1-0472 (AFOSR, PI, A. Hanke), SC2GM081218 and SC3GM099637 (NIH, PI, Natalia Valentinova Guevara). Mr. Troy McWhorter donated his time and effort on this project. Mr. Jamie Romo Jr. was supported by R25GM083755 (NIH, PIs, J. Facelli, S. Nair).

\section{References}

[1] R. J. Kuhn, W. Zhang, M. G. Rossmann et al., "Structure of dengue virus: implications for flavivirus organization, maturation, and fusion," Cell, vol. 108, no. 5, pp. 717-725, 2002.

[2] E. V. Orlova, M. B. Sherman, W. Chiu, H. Mowri, L. C. Smith, and A. M. Gotto Jr., "Three-dimensional structure of low density lipoproteins by electron cryomicroscopy," Proceedings of the National Academy of Sciences of the United States of America, vol. 96, no. 15, pp. 8420-8425, 1999.

[3] A. M. Scanu and C. Wisdom, "Serum lipoproteins structure and function," Annual Review of Biochemistry, vol. 41, pp. 703-730, 1972.

[4] B. D. Lindenbach, H.-J. Thiel, and C. M. Rice, "Flaviviridae: the viruses and their replication," in Fields Virology, D. M. Knipe and P. M. Howley, Eds., chapter 33, pp. 1101-1152, Lippincott Williams \& Wilkins, Philadelphia, Pa, USA, 2006.

[5] J. Guevara Jr., N. Prashad, B. Ermolinsky et al., "Apo B100 similarities to viral proteins suggest basis for LDL-DNA binding and transfection capacity," The Journal of Lipid Research, vol. 51, no. 7, pp. 1704-1718, 2010.

[6] D. J. Gubler, G. Kuno, and L. Markoff, "Flaviviruses," in Fields Virology, D. M. Knipe and P. M. Howley, Eds., chapter 34, pp. 1153-1252, Lippincott Williams \& Wilkins, Philadelphia, Pa, USA, 2006.

[7] E. A. Gould and T. Solomon, "Pathogenic flaviviruses," The Lancet, vol. 371, no. 9611, pp. 500-509, 2008.

[8] W. Fischl and R. Bartenschlager, "Exploitation of cellular pathways by Dengue virus," Current Opinion in Microbiology, vol. 14, no. 4, pp. 470-475, 2011.

[9] S. Mukhopadhyay, R. J. Kuhn, and M. G. Rossmann, "A structural perspective of the Flavivirus life cycle," Nature Reviews Microbiology, vol. 3, no. 1, pp. 13-22, 2005.

[10] C. Mosso, I. J. Galván-Mendoza, J. E. Ludert, and R. M. del Angel, "Endocytic pathway followed by dengue virus to infect the mosquito cell line C6/36 HT," Virology, vol. 378, no. 1, pp. 193-199, 2008.

[11] J. Mercer, M. Schelhaas, and A. Helenius, "Virus entry by endocytosis," Annual Review of Biochemistry, vol. 79, pp. 803$833,2010$.

[12] H. M. van der Schaar, M. J. Rust, H. van der Ende-Metselaar, J. Wilschut, X. Zhuang, and J. M. Smit, "Dissecting the cell entry pathway of dengue virus by single-particle tracking in living cells," PLoS Pathogens, vol. 4, no. 12, Article ID e1000244, 2008.

[13] S. B. Halstead, F. X. Heinz, A. D. T. Barrett, and J. T. Roehrig, "Dengue virus: molecular basis of cell entry and pathogenesis, 
25-27 June 2003, Vienna, Austria," Vaccine, vol. 23, no. 7, pp. 849-856, 2005.

[14] W. D. Crill and J. T. Roehrig, "Monoclonal antibodies that bind to domain III of dengue virus $\mathrm{E}$ glycoprotein are the most efficient blockers of virus adsorption to vero cells," Journal of Virology, vol. 75, no. 16, pp. 7769-7773, 2001.

[15] H. Karlsson, P. Leanderson, C. Tagesson, and M. Lindahl, "Lipoproteomics I: mapping of proteins in low-density lipoprotein using two-dimensional gel electrophoresis and mass spectrometry," Proteomics, vol. 5, no. 2, pp. 551-565, 2005.

[16] H.-Y. Sun, S.-F. Chen, M.-D. Lai et al., "Comparative proteomic profiling of plasma very-low-density and low-density lipoproteins," Clinica Chimica Acta, vol. 411, no. 5-6, pp. 336-344, 2010.

[17] J. Callow, L. K. M. Summers, H. Bradshaw, and K. N. Frayn, "Changes in LDL particle composition after the consumption of meals containing different amounts and types of fat," The American Journal of Clinical Nutrition, vol. 76, no. 2, pp. 345$350,2002$.

[18] R. Prassl, "Human low density lipoprotein: the mystery of core lipid packing," Journal of Lipid Research, vol. 52, no. 2, pp. 187188, 2011.

[19] J. L. Goldstein and M. S. Brown, "History of discovery: the LDL receptor," Arteriosclerosis, Thrombosis, and Vascular Biology, vol. 29, pp. 431-438, 2009.

[20] C. A. Dyer, D. P. Cistola, G. C. Parry, and L. K. Curtiss, "Structural features of synthetic peptides of apolipoprotein E that bind the LDL receptor," The Journal of Lipid Research, vol. 36, no. 1, pp. 80-88, 1995.

[21] C.-Y. Yang, S.-H. Chen, S. H. Gianturco et al., "Sequence, structure, receptor-binding domains and internal repeats of human apolipoprotein B-100," Nature, vol. 323, no. 6090, pp. 738-742, 1986.

[22] A. V. Hospattankar, S. W. Law, K. Lackner, and H. B. Brewer Jr., "Identification of low density lipoprotein receptor binding domains of human apolipoprotein B-100: a proposed consensus LDL receptor binding sequence of apoB-100," Biochemical and Biophysical Research Communications, vol. 139, no. 3, pp. 1078$1085,1986$.

[23] M. Guttman, J. H. Prieto, J. E. Croy, and E. A. Komives, "Decoding of lipoprotein-receptor interactions: properties of ligand binding modules governing interactions with apolipoprotein E," Biochemistry, vol. 49, no. 6, pp. 1207-1216, 2010.

[24] A. D. Cardin and H. J. R. Weintraub, "Molecular modeling of protein-glycosaminoglycan interactions," Arteriosclerosis, Thrombosis, and Vascular Biology, vol. 9, no. 1, pp. 21-32, 1989.

[25] A. D. Murdoch, G. R. Dodge, I. Cohen, R. S. Tuan, and R. V. Iozzo, "Primary structure of the human heparan sulfate proteoglycan from basement membrane (HSPG2/perlecan). A chimeric molecule with multiple domains homologous to the low density lipoprotein receptor, laminin, neural cell adhesion molecules, and epidermal growth factor," The Journal of Biological Chemistry, vol. 267, no. 12, pp. 8544-8557, 1992.

[26] L. Ma, C. T. Jones, T. D. Groesch, R. J. Kuhn, and C. B. Post, "Solution structure of dengue virus capsid protein reveals another fold," Proceedings of the National Academy of Sciences of the United States of America, vol. 101, no. 10, pp. 3414-3419, 2004.

[27] C. Wilson, M. R. Wardell, K. H. Weisgraber, R. W. Mahley, and D. A. Agard, "Three-dimensional structure of the LDL receptorbinding domain of human apolipoprotein E," Science, vol. 252, no. 5014, pp. 1817-1822, 1991.
[28] M. Zaiou, K. S. Arnold, Y. M. Newhouse et al., "Apolipoprotein E-low density lipoprotein receptor interaction: influences of basic residue and amphipathic $\alpha$-helix organization in the ligand," Journal of Lipid Research, vol. 41, no. 7, pp. 1087-1095, 2000.

[29] M. Guttman, J. H. Prieto, T. M. Handel, P. J. Domaille, and E. A. Komives, "Structure of the minimal interface between ApoE and LRP," Journal of Molecular Biology, vol. 398, no. 2, pp. 306319, 2010.

[30] C. A. Dyer and L. K. Curtiss, "A synthetic peptide mimic of plasma apolipoprotein E that binds the LDL receptor," The Journal of Biological Chemistry, vol. 266, no. 34, pp. 2280322806, 1991.

[31] I. R. Nikoulin and L. K. Curtiss, "An apolipoprotein E synthetic peptide targets to lipoproteins in plasma and mediates both cellular lipoprotein interactions in vitro and acute clearance of cholesterol-rich lipoproteins in vivo," The Journal of Clinical Investigation, vol. 101, no. 1, pp. 223-234, 1998.

[32] Y.-H. Hsieh and C.-Y. Chou, "Structural and functional characterization of human apolipoprotein E 72-166 peptides in both aqueous and lipid environments," Journal of Biomedical Science, vol. 18, no. 1, article 4, 2011.

[33] D. J. Christensen, N. Ohkubo, J. Oddo et al., "Apolipoprotein $\mathrm{E}$ and peptide mimetics modulate inflammation by binding the SET protein and activating protein phosphatase $2 \mathrm{~A}$," The Journal of Immunology, vol. 186, no. 4, pp. 2535-2542, 2011.

[34] C. B. Dobson, S. D. Sales, P. Hoggard, M. A. Wozniak, and K. A. Crutcher, "The receptor-binding region of human apolipoprotein E has direct anti-infective activity," The Journal of Infectious Diseases, vol. 193, no. 3, pp. 442-450, 2006.

[35] S. Liu, K. D. McCormick, W. Zhao, T. Zhao, D. Fan, and T. Wang, "Human apolipoprotein E peptides inhibit hepatitis C virus entry by blocking virus binding," Hepatology, vol. 56, no. 2, pp. 484-491, 2012.

[36] B. A. Kelly, S. J. Neil, Á. McKnight et al., "Apolipoprotein Ederived antimicrobial peptide analogues with altered membrane affinity and increased potency and breadth of activity," FEBS Journal, vol. 274, no. 17, pp. 4511-4525, 2007.

[37] N. Beglova, H. Jeon, C. Fisher, and S. C. Blacklow, "Structural features of the low-density lipoprotein receptor facilitating ligand binding and release," Biochemical Society Transactions, vol. 32, no. 5, pp. 721-723, 2004.

[38] C. Fisher, D. Abdul-Aziz, and S. C. Blacklow, "A two-module region of the low-density lipoprotein receptor sufficient for formation of complexes with apolipoprotein E ligands," Biochemistry, vol. 43, no. 4, pp. 1037-1044, 2004.

[39] S. D. Roosendaal, J. M. van Doorn, K. M. Valentijn, D. J. van der Horst, and K. W. Rodenburg, "Delipidation of insect lipoprotein, lipophorin, affects its binding to the lipophorin receptor, LpR: implications for the role of LpR-mediated endocytosis," Insect Biochemistry and Molecular Biology, vol. 39, no. 2, pp. 135$144,2009$.

[40] H.-M. Cheon, W. S. Sang, G. Bian, J.-H. Park, and A. S. Raikhel, "Regulation of lipid metabolism genes, lipid carrier protein lipophorin, and its receptor during immune challenge in the mosquito Aedes aegypti," The Journal of Biological Chemistry, vol. 281, no. 13, pp. 8426-8435, 2006.

[41] K. W. Rodenburg and D. J. van der Horst, "Review. Lipoproteinmediated lipid transport in insects: analogy to the mammalian lipid carrier system and novel concepts for the functioning of LDL receptor family members," Biochimica et Biophysica Acta, vol. 1736, no. 1, pp. 10-29, 2005. 
[42] P. W. Atkinson, J. Hemingway, B. M. Christensen et al., "Annotation of Culex pipiens quinquefasciatus," http://www.ncbi.nlm .nih.gov/protein/XP_001864948.

[43] M. C. van Heusden, F. Thompson, and J. Dennis, "Biosynthesis of Aedes aegypti lipophorin and gene expression of its apolipoproteins," Insect Biochemistry and Molecular Biology, vol. 28, no. 10, pp. 733-738, 1998.

[44] H. M. Cheon, S. J. Seo, J. Sun, T. W. Sappington, and A. S. Raikhel, "Molecular characterization of the VLDL receptor homolog mediating binding of lipophorin in oocyte of the mosquito Aedes aegypti," Insect Biochemistry and Molecular Biology, vol. 31, no. 8, pp. 753-760, 2001.

[45] T. W. Sappington and A. S. Raikhel, "Ligand-binding domains in vitellogenin receptors and other LDL-receptor family members share a common ancestral ordering of cysteine-rich repeats," Journal of Molecular Evolution, vol. 46, no. 4, pp. 476-487, 1998.

[46] B. A. Kumar and K. P. Paily, "Up-regulation of lipophorin (Lp) and lipophorin receptor (LpR) gene in the mosquito, Culex quinquefasciatus (Diptera: Culicidae), infected with the filarial parasite, Wuchereria bancrofti (Spirurida: Onchocercidae)," Parasitology Research, vol. 108, no. 2, pp. 377-381, 2011.

[47] G. W. Rebeck, M. J. LaDu, S. Estus, G. Bu, and E. J. Weeber, "The generation and function of soluble apo E receptors in the CNS," Molecular Neurodegeneration, vol. 1, no. 1, article 15, pp. 1-13, 2006.

[48] J. M. Smit, B. Moesker, I. Rodenhuis-Zybert, and J. Wilschut, "Flavivirus cell entry and membrane fusion," Viruses, vol. 3, no. 2, pp. 160-171, 2011.

[49] Y. Chen, T. Maguire, R. E. Hileman et al., "Dengue virus infectivity depends on envelope protein binding to target cell heparan sulfate," Nature Medicine, vol. 3, no. 8, pp. 866-871, 1997.

[50] D. Watterson, B. Kobe, and P. R. Young, "Residues in domain III of the dengue virus envelope glycoprotein involved in cell-surface glycosaminoglycan binding," Journal of General Virology, vol. 93, no. 1, pp. 72-82, 2012.

[51] A. Cabrera-Hernandez and D. R. Smith, "Mammalian dengue virus receptors," Dengue Bulletin, vol. 29, pp. 119-135, 2005.

[52] J. Reyes-del Valle, J. Salas-Benito, R. Soto-Acosta, and R. M. del Angel, "Dengue virus cellular receptors and tropism," Current Tropical Medicine Reports, vol. 1, no. 1, pp. 36-43, 2014.

[53] M. S. Paingankar, M. D. Gokhale, and D. N. Deobagkar, "Dengue-2-virus-interacting polypeptides involved in mosquito cell infection," Archives of Virology, vol. 155, no. 9, pp. 1453-1461, 2010.

[54] K. Jessie, M. Y. Fong, S. Devi, S. K. Lam, and K. T. Wong, "Localization of dengue virus in naturally infected human tissues, by immunohistochemistry and in situ hybridization," The Journal of Infectious Diseases, vol. 189, no. 8, pp. 1411-1418, 2004.

[55] M. S. Diamond, D. Edgil, T. G. Roberts, B. Lu, and E. Harris, "Infection of human cells by dengue virus is modulated by different cell types and viral strains," Journal of Virology, vol. 74, no. 17, pp. 7814-7823, 2000.

[56] M. N. Krishnan, B. Sukumaran, U. Pal et al., "Rab 5 is required for the cellular entry of dengue and West Nile viruses," Journal of Virology, vol. 81, no. 9, pp. 4881-4885, 2007.

[57] P.-Y. Lozach, L. Burleigh, I. Staropoli et al., "Dendritic cell-specific intercellular adhesion molecule 3-grabbing nonintegrin (DC-SIGN)-mediated enhancement of dengue virus infection is independent of DC-SIGN internalization signals,"
Journal of Biological Chemistry, vol. 280, no. 25, pp. 2369823708, 2005.

[58] B. Tassaneetrithep, T. H. Burgess, A. Granelli-Piperno et al., "DC-SIGN (CD209) mediates dengue virus infection of human dendritic cells," The Journal of Experimental Medicine, vol. 197, no. 7, pp. 823-829, 2003.

[59] S. Noisakran, N. Onlamoon, P. Songprakhon, H.-M. Hsiao, K. Chokephaibulkit, and G. C. Perng, "Cells in dengue virus infection in vivo," Advances in Virology, vol. 2010, Article ID 164878, 15 pages, 2010.

[60] W.-H. Kwan, E. Navarro-Sanchez, H. Dumortier et al., "Dermal-type macrophages expressing CD209/DC-SIGN show inherent resistance to dengue virus growth," PLoS Neglected Tropical Diseases, vol. 2, no. 10, article e311, 2008.

[61] A.-R. Goncalves, M.-L. Moraz, A. Pasquato, A. Helenius, P.-Y. Lozach, and S. Kunza, "Role of DC-SIGN in lassa virus entry into human dendritic cells," Journal of Virology, vol. 87, no. 21, pp. 11504-11515, 2013.

[62] X.-X. Ren, L. Ma, Q.-W. Liu et al., "The molecule of DC-SIGN captures enterovirus 71 and confers dendritic cell-mediated viral trans-infection," Virology Journal, vol. 11, no. 1, article 47, 2014.

[63] M. L. Williams, A. M. Mommaas-Kienhuis, S. L. Rutherford, S. Grayson, B. J. Vermeer, and P. M. Elias, "Free sterol metabolism and low density lipoprotein receptor expression as differentiation markers of cultured human keratinocytes," Journal of Cellular Physiology, vol. 132, no. 3, pp. 428-440, 1987.

[64] M.-F. Galliano, E. Toulza, N. Jonca, S. L. Gonias, G. Serre, and M. Guerrin, "Binding of $\alpha 2 \mathrm{ML1}$ to the low density lipoprotein receptor-related protein 1 (LRP1) reveals a new role for LRP1 in the human epidermis," PLoS ONE, vol. 3, no. 7, Article ID e2729, 2008.

[65] J. N. W. N. Barker, R. S. Mitra, C. E. M. Griffiths, V. M. Dixit, and B. J. Nickoloff, "Keratinocytes as initiators of inflammation," The Lancet, vol. 337, no. 8735, pp. 211-214, 1991.

[66] T. Nickel, D. Schmauss, H. Hanssen et al., "oxLDL uptake by dendritic cells induces upregulation of scavenger-receptors, maturation and differentiation," Atherosclerosis, vol. 205, no. 2, pp. 442-450, 2009.

[67] Y. Chen, T. Maguire, and R. M. Marks, "Demonstration of binding of dengue virus envelope protein to target cells," Journal of Virology, vol. 70, no. 12, pp. 8765-8772, 1996.

[68] S. M. Erb, S. Butrapet, K. J. Moss et al., "Domain-III FG loop of the dengue virus type 2 envelope protein is important for infection of mammalian cells and Aedes aegypti mosquitoes," Virology, vol. 406, no. 2, pp. 328-335, 2010.

[69] A. K. I. Falconar, "Use of synthetic peptides to represent surfaceexposed epitopes defined by neutralizing dengue complex- and flavivirus group-reactive monoclonal antibodies on the native dengue type-2 virus envelope glycoprotein," Journal of General Virology, vol. 89, no. 7, pp. 1616-1621, 2008.

[70] F. Megret, J. P. Hugnot, A. Falconar et al., "Use of recombinant fusion proteins and monoclonal antibodies to define linear and discontinuous antigenic sites on the dengue virus envelope glycoprotein," Virology, vol. 187, no. 2, pp. 480-491, 1992.

[71] A. F. Faustino, F. A. Carvalho, I. C. Martins et al., "Dengue virus capsid protein interacts specifically with very low-density lipoproteins," Nanomedicine, vol. 10, no. 1, pp. 247-255, 2014.

[72] S.-H. Wang, W.-J. Syu, K.-J. Huang et al., "Intracellular localization and determination of a nuclear localization signal of the core protein of dengue virus," Journal of General Virology, vol. 83, no. 12, pp. 3093-3102, 2002. 
[73] M. M. Samsa, J. A. Mondotte, N. G. Iglesias et al., "Dengue virus capsid protein usurps lipid droplets for viral particle formation," PLoS Pathogens, vol. 5, no. 10, Article ID e1000632, 2009.

[74] C. A. Balinsky, H. Schmeisser, S. Ganesan, K. Singh, T. C. Pierson, and K. C. Zoon, "Nucleolin interacts with the dengue virus capsid protein and plays a role in formation of infectious virus particles," Journal of Virology, vol. 87, no. 24, pp. 1309413106, 2013

[75] Y.-S. Lin, T.-M. Yeh, C.-F. Lin et al., "Molecular mimicry between virus and host and its implications for dengue disease pathogenesis," Experimental Biology and Medicine, vol. 236, no. 5, pp. 515-523, 2011.

[76] D. T. Trung and B. Wills, "Systemic vascular leakage associated with dengue infections-The Clinical Perspective," in Dengue Virus, A. L. Rothman, Ed., vol. 338 of Current Topics in Microbiology and Immunology, pp. 57-66, Springer, Berlin, Germany, 2010. 

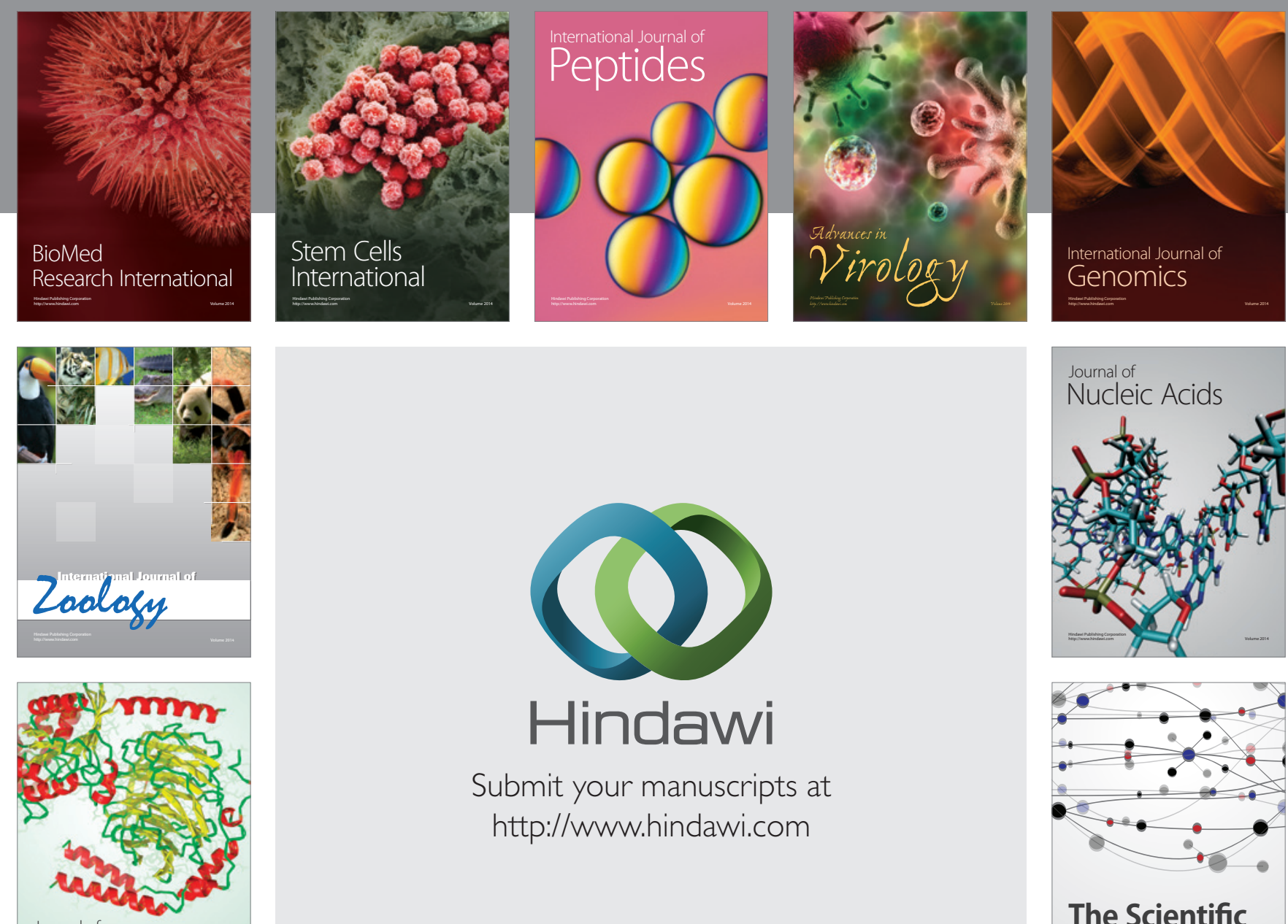

Submit your manuscripts at

http://www.hindawi.com

Journal of
Signal Transduction
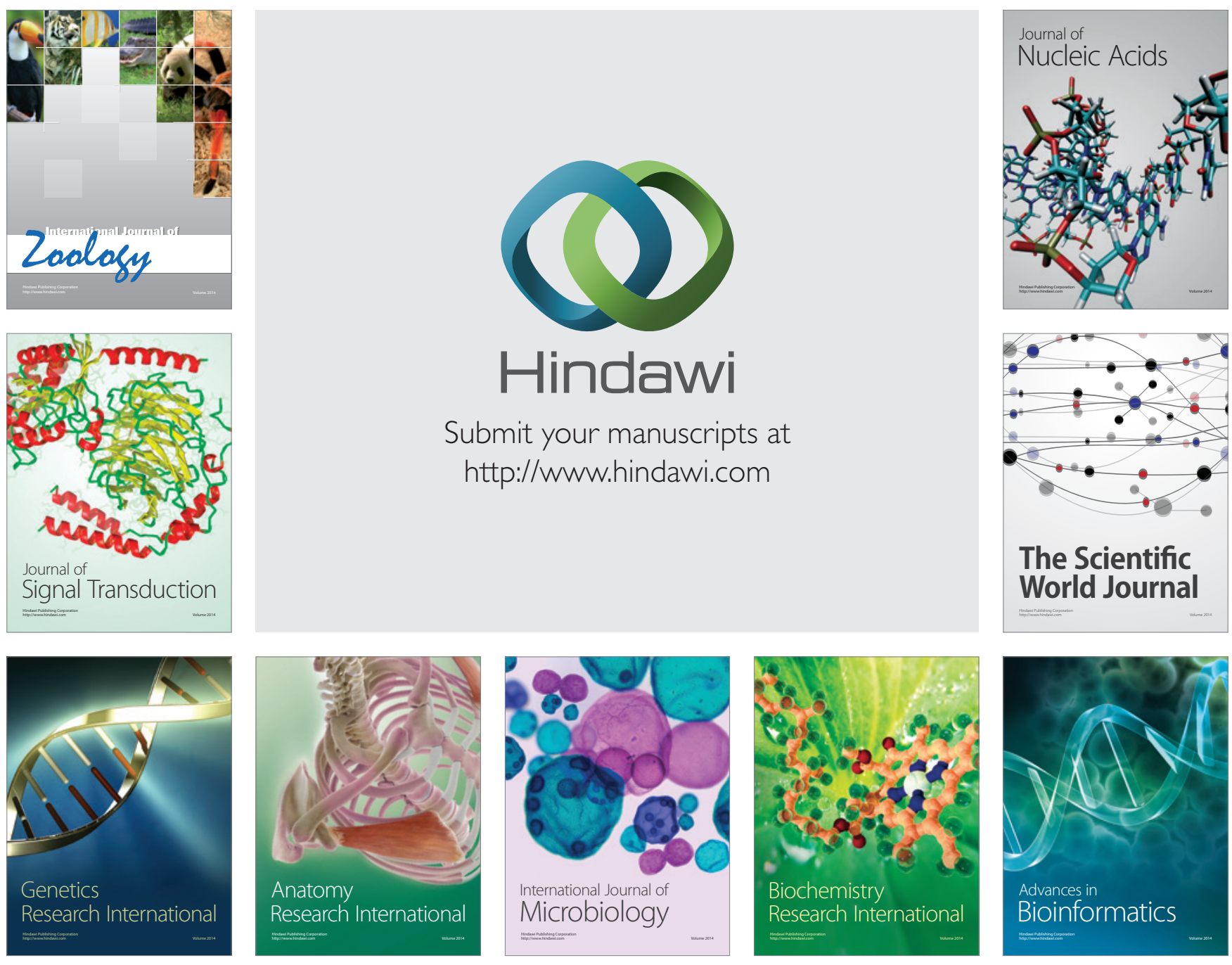

The Scientific World Journal
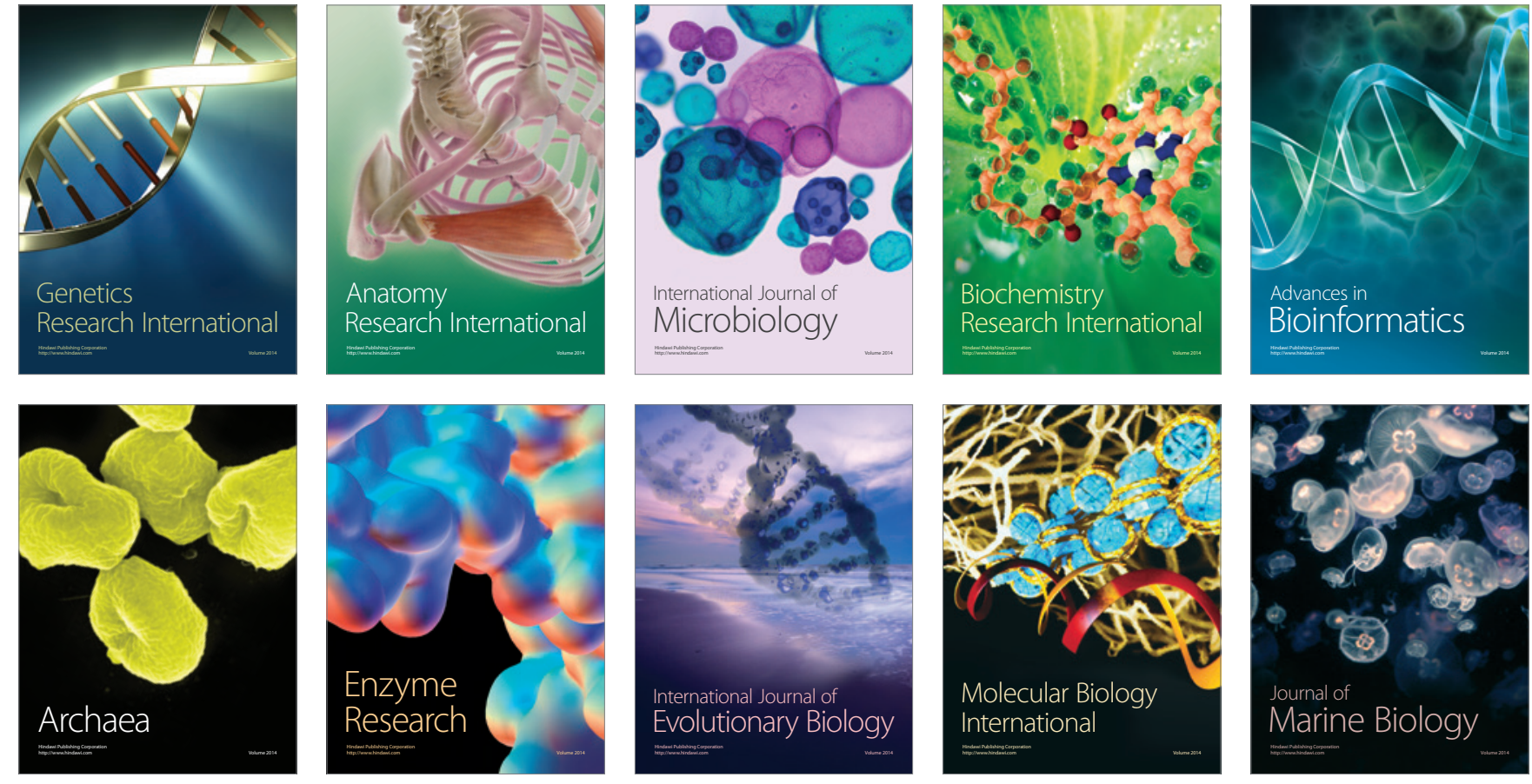